\title{
Nanotechnology-Based Drug Delivery Systems for Melanoma Antitumoral Therapy: A Review
}

\author{
Roberta Balansin Rigon, Márcia Helena Oyafuso, \\ Andressa Terumi Fujimura, Maíra Lima Gonçalez, Alice Haddad do Prado, \\ Maria Palmira Daflon Gremião, and Marlus Chorilli \\ School of Pharmaceutical Sciences, Department of Drug and Medicines, São Paulo State University, 14801-902 Araraquara, SP, Brazil \\ Correspondence should be addressed to Marlus Chorilli; chorilli@fcfar.unesp.br
}

Received 9 January 2015; Revised 6 April 2015; Accepted 7 April 2015

Academic Editor: Fabio Sonvico

Copyright (C) 2015 Roberta Balansin Rigon et al. This is an open access article distributed under the Creative Commons Attribution License, which permits unrestricted use, distribution, and reproduction in any medium, provided the original work is properly cited.

\begin{abstract}
Melanoma (MEL) is a less common type of skin cancer, but it is more aggressive with a high mortality rate. The World Cancer Research Fund International (GLOBOCAN 2012) estimates that there were 230,000 new cases of MEL in the world in 2012. Conventional MEL treatment includes surgery and chemotherapy, but many of the chemotherapeutic agents used present undesirable properties. Drug delivery systems are an alternative strategy by which to carry antineoplastic agents. Encapsulated drugs are advantageous due to such properties as high stability, better bioavailability, controlled drug release, a long blood circulation time, selective organ or tissue distribution, a lower total required dose, and minimal toxic side effects. This review of scientific research supports applying a nanotechnology-based drug delivery system for MEL therapy.
\end{abstract}

\section{Introduction}

Malignant melanoma (MEL) are tumors that mainly affect adult and elderly patients; the highest incidence is at approximately 60 years of age [1]. However, currently, MEL recurrence has increased in young adults and can be observed in children and adolescents [2].

The World Cancer Research Fund International (GLOBOCAN 2012) estimates that there were 230,000 new cases of MEL in the world in 2012; MEL incidence rates are much higher in the White population than in the Black population, and it is uncommon in the Asian population, likely due to better protection from their skin pigment and different sun exposure habits; African and Asian societies consider fair skin beautiful [3]. In addition, rich populations have a high rate of MEL with a relatively low rate of mortality from this disease, potentially because MEL is diagnosed in early stages for this social class [4-6].

Pathogenesis of Melanoma. Melanocytic skin tumors include a wide variety of benign and malignant skin lesions with distinct clinical, morphological, and genetic profiles [7-9].
Melanoma describes melanocyte malignance; a melanocyte is a melanin-producing cell located in the basal layer of the epidermis [10]. When it functions normally, the melanocyte provides basic skin pigmentation and protects against UV radiation damage [11-13].

In summary, the most significant causes of MEL development are at personal history of MEL in the family, advanced age, the presence an atypical nevus, intense exposure to sunlight, sunburn during childhood [14], and chronic immunosuppression [15]; it is especially observed in posttransplant patients and patients with acquired immunodeficiency syndrome (AIDS) or a prior cancer diagnosis [11].

Genetic predisposition plays an important role in MEL development due to the relative risk of people with a family history of MEL developing this cancer, which is 2-3 times greater than in people without such a family history; several genes (CDKN2A; BRAFV600E; N-Ras codon 61; CKIT; GNAQ/GNA11; BRCA2; OCA1 and MC1R) related to this predisposition have been identified [2, 16-20].

UV radiation also has a profound influence on MEL development. Sunscreens use, which protect the skin against this radiation, does not prevent MEL development, because 
the UV radiation spectrum that causes erythema (UVB) and that traditional sunscreens protect against differ from the spectrum that promotes MEL (UVA). Thus, users of sunscreens are relatively unprotected from UVA radiation [11]. An alternative theory suggests that vitamin D, which inhibits the signaling pathway involved in MEL development [21] (i.e., the MAP kinase pathway that promotes cell proliferation), is synthesized upon UV radiation, and when radiation is blocked by sunscreen, vitamin D synthesis stops [22, 23].

The cutaneous MEL is manifested in different regions of the body through lesions on the head and neck and is associated with chronic sun exposure and lesions on the trunk related to the presence of numerous melanocytic nevi [24].

Almost all MEL lesions are pigmented and flat; malignant melanocytes growth is restricted to the epidermis ("MEL in situ"), and the cells are characterized by a relatively homogeneous brown pigmentation with slightly irregular edges $[25,26]$. Over time, likely many years, these lesions present with irregular edges and pigmentation. In late stages, this neoplastic growth is vertical, and the tumor cells infiltrate through collagen fibers in the reticular dermis [27]. The subcutaneous tissue is then infiltrated by the tumor, which forms papules and nodules, and is typically confined to the lesion area [28]. Partial regression of the lesion is common, which functions through an immune mediated phenomenon that promotes malignant melanocyte elimination by cytotoxic lymphocytes [29]. However, complete MEL regression may be associated with the spread of metastasis, which is a negative, not positive prognostic sign $[2,30]$.

For melanocyte transformation in MEL, resistance to apoptosis is necessary [31], and MELs escape from apoptosis stimulation through overexpressing apoptosis-inhibiting genes (e.g., inhibitor of apoptosis proteins (IAPs), especially survivin) or decreasing apoptosis-inducing gene expression, which results in apoptosis dysfunction and an increased risk of metastasis [32]. The serine/threonine kinase Akt/protein kinase $\mathrm{B}$ and transcription factor nuclear factor $\kappa \beta$ (NF$\kappa \beta)$ participate in the cell proliferation control, apoptosis, and oncogenesis [33], and certain studies suggest that Akt activation can facilitate MEL progression by increasing cells survival through NF- $\kappa \beta$ regulation with a consequent reduction in apoptosis [20].

Classification of Melanoma and Diagnoses. MEL is clinically classified into four main groups [34]. The first group is lentigo maligna MEL, which is characterized by an invasive tumor in the head, neck, or forearms regions [35]. Another group is superficial-spreading MEL, which is characterized by a lesion with irregular edges and pigmentation that grows laterally and slowly before promoting vertical invasion [36]. The next group is nodular MEL, which is a more aggressive type that appears in the body following high levels of sunlight exposure [37]. The final group is acral lentiginous MEL, which are pigmented lesions that appear on the palms of the hands, soles of the feet, and above the nose $[38,39]$. Other classifications include amelanotic MEL, mucosal MEL, and subungual MEL [2].
For MEL diagnosis, five main characteristics of the lesion are analyzed: asymmetry, border-color, diameter, and elevation; MEL diagnoses are more accurate where dermatoscopy is used [11]. However, for many people, the first area that metastasizes is the lymph node (sentinel); the next most common site of metastasis is distant skin. The organs more frequently affected are the lungs and the liver; the central nervous system and bones can also be metastasis sites $[40,41]$.

The MEL stage can be determined through a complete clinical examination [42], including sonography [43] of the superficial lymph nodes and the abdomen, radiography of the thorax [44], and evaluation of serum markers, such as lactate dehydrogenase (LDH) [45], S-100-beta, sialic acid, enolase, 5S-cyseinyldopa, 6-hydroxy-5-methyoxy-indole-2-carboxylic acid, 3,4-dihydroxy-L-phenylalanine (DOPA), L-tyrosine [46], computer tomography scan [47], magnetic resonance imaging [48], bone scintigraphy [49], and positron emission tomography, which are useful for evaluating patients with metastatic disease [50].

Moreover, an immunohistochemical technique can also be used to diagnose metastasis because antigens are expressed on malignant cells' membrane and cytoplasm surface, which can be immunohistochemically detected using antibodies that are specific to these antigens [51]. The antibodies commonly used are anti-S100, HMB-45, and MART-1 e NK1/C3.

Conventional Therapeutic Strategies against Melanoma. Chemoprevention can be used to avoid MEL development; chemoprevention was originally proposed by Sporn et al. (1976) [52] and refers to using synthetic or natural agents to reverse, suppress, or prevent molecular and histological premalignant lesions that occur with invasive cancer progression [20]. Reactive oxygen species play a role in MEL progression because they lead to uncontrolled overregulation and compartmentalization of melanosomes [53], a diet rich in antioxidants, particularly carotenoids and vitamins $\mathrm{C}$ and E, which can be used for chemoprevention $[54,55]$.

The conventional treatment for primary MEL is surgical; the lesion is removed, and the tissue is analyzed to determine the MEL stage, which depend on the lesion thickness and location (epidermis or dermis). The lesion is removed with a certain safety margin; however, where lesion excision is inappropriate, such as for MELs in the nasopharyngeal, sinonasal, and oral regions, radiotherapy is a way to eliminate the lesion. For patients who present risk of metastasis, the above indicated laboratory tests are also used, such as radiography of the thorax $[11,56,57]$.

The conventional MEL chemotherapy treatment is performed using dacarbazine, temozolomide (dacarbazine analogue), nitrosoureas (carmustine, lomustine), vinca alkaloids (vincristine, vinblastine), platinum compounds (cisplatin, carboplatin), and taxanes (Taxol, docetaxel), but these single agents are not an improvement over dacarbazine [32, 58]. Immunotherapy has also been applied for MEL therapy; immunotherapy employs cytokines that stimulate the patient's immune system to fight cancer, such as interleukin (IL), IL-2, IL-5, IL-7, and IL-21, interferon- $\alpha$ (INF- $\alpha$ ), and 
granulocyte macrophage colony-stimulating factor (GMCSF) [59]. These cytokines have side effects, such as diarrhea, nausea, constipation, abdominal pain, vomiting, vitiligo, dermatitis, enterocolitis, hepatitis, toxic epidermal necrolysis, neuropathy, and endocrinopathy [11].

The benefits of therapy with interferon alfa-2b are directly related to the MEL stage [60]. However, high interferon alfa$2 \mathrm{~b}$ doses have many side effects, such as chronic fatigue, headaches, weight loss, myelosuppression, and depression [61].

Vemurafenib and dabrafenib are BRAF inhibitors approved for use in MEL metastases that express BRAFV600E and lead to dramatic shrinkage of tumors. However, they are short-lived and resistance to treatment eventually emerges in most melanomas. In addition, treatment with BRAF inhibitors can lead to the induction of second primary cancers, including squamous cell carcinomas of the skin and new primary BRAF wildtype melanomas; other side effects are nausea, diarrhea, arthralgias, nonspecific skin rashes, fatigue, alopecia, and photosensitivity [62-64].

Tremelimumab is an antibody against the cytotoxic $\mathrm{T}$ lymphocyte-associated antigen 4 and is well-tolerated, but it does not offer many benefits over conventional chemotherapy [65].

Ipilimumab is a humanized antibody against CTLA-4, a negative regulatory checkpoint protein that is expressed on $\mathrm{T}$ cells surface after activation; the ipilimumab specifically blocks the CTLA-4 inhibitory signal, resulting in activation of T cells and tumour infiltrating lymphocytes; this is an indirect mechanism that enhances the immune response mediated by $\mathrm{T}$ cells. The adverse effects are colitis, dermatitis, hepatitis, endocrinopathy, and neuritis $[63,66]$.

Nivolumab and pembrolizumab are anti-PD-1 antibodies; PD-1, like CTLA-4, is expressed on the surface of activated $\mathrm{T}$ cells and has a function to turn off the T-cell response to prevent an excessive immune reaction. Anti-PD-1 antibodies may have higher response and lower toxicity rates than ipilimumab, as well as improved overall survival compared to chemotherapy $[63,66,67]$.

Studies demonstrated that a combination therapy with ipilimumab and nivolumad was responsible for more adverse effects than monotherapy; on the other hand the patient's median survival was higher when patients were treated with combination therapy [66]. Therefore, several studies are being realized to evaluate the potential survival benefits of immunotherapy combination [68].

\section{Nanotechnology-Based Drug Delivery Systems}

Many active ingredients used in MEL therapy present undesirable properties and, thus, have been discarded [69]. Introducing a new active ingredient on the market takes several years of research and involves high costs. The alternative employed to circumvent these high costs and reintroduce the active ingredients that were previously discarded is the development of delivery systems that increase efficiency [70].
Drug delivery systems represent an alternative strategy to carrier antineoplastic agents. Encapsulated drug could result in advantages such as high stability, better bioavailability, controlled drug release, long circulation time in blood, selective organs or tissue distribution, a reduction of the total dose required, and minimizing the toxic side effects [71-73]. Nanotechnology-based drug delivery systems are widely used to improve the effectiveness of antineoplastic agent; the most common nanosystems are hydrogel, cyclodextrins, liquid crystalline phase, and nanoparticulate pharmaceutical drug delivery systems (NDDSs), as classified by Torchilin (2014), that include liposomes; polymeric nanoparticles; polymeric micelles; silica, gold, silver, and other metal nanoparticles; carbon nanotubes; solid lipid nanoparticles; niosomes; and dendrimers [74]. This review of scientifically based research supports the application of nanotechnology-based drug delivery system for MEL therapy.

2.1. Hydrogels. Polymeric systems can be classified by their physical forms such as (i) linear polymer chain in solution, (ii) physically or covalently cross-linked reversible gels, and (iii) polymer chains grafting or adsorption on the surface of micro- and nanoparticles [75]. A hydrogel is a network of polymer chains that are hydrophilic and promote the drug release through the spaces formed in the network via dissolution or disintegration of the polymeric matrix. Swelling in certain non-water-soluble polymer demonstrates a high water absorption capacity in the reticular structure $(>20 \%)[76,77]$.

An increased interest in hydrogels as a drug delivery system has been demonstrated as a result of their easy handling and similar physical properties to animal tissue, which depend on the polymer employed [78-80]. The release rate depends on the hydrogel properties, initial drug concentration, drug solubility, and drug-polymer interaction [81].

A wide variety of polymeric materials with different properties have been used to form hydrogels. The required polymer is selected based on the tissue of interest and the specific application [80, 82]. For example, poly(vinyl alcohol) tetrahydroxyborate (PVA-THB) hydrogels have shown therapeutic potential for topically treating acute and chronic wounds due to many benefits, such as controlled release, bioadhesion, and low toxicity $[83,84]$. Moreover, chitosanbased hydrogels have an additional advantage as a drug delivery system because the drug can be released under various environmental stimuli; thus, these hydrogels provide an anchor for delivering therapeutic payloads to the site of action [85].

Hydrogels have been employed as a drug delivery system in MEL therapy because they may act as an intratumoral chemotherapy depot by promoting accumulation or maintenance of high intracellular levels of the chemotherapeutic agent. In recent years, a hydrogel composed of a cyclodextrincontaining linear polymer and decorated with PEG as well as transferrin was approved for commercial use in MEL therapy [86].

Hydrogels are classified as stimuli-sensitive swellingcontrolled release systems because they can respond to 
various environmental conditions, such as $\mathrm{pH}$, the surrounding fluid ionic strength, temperature, an applied electrical or magnetic field, or glucose level changes. These changes promote altered network structure, swelling, mechanical strength and permeability [83]. Thus, hydrogels may be used to improve drug delivery [87-90]. However, little evidence supports using hydrogels for topical treatment of MEL.

Certain studies suggest using topical hydrogels; topical ibuprofen-releasing hydrogels promote lower metastatic spread of primary MEL through significantly lower tumor necrosis factor (TNF) - $\alpha$ levels, which is the major proinflammatory cytokine that induces MEL cell migrations [91].

Injectable hydrogels have been widely explored for cancer therapy [85, 92]. Interleukin-2 was given as pulse in cancer immunotherapy because it is a potent immunomodulator that can induce antitumor activity [93]. Recombinant human interleukin-2 (rhIL-2) loaded, in situ gelling, and physically cross-linked dextran hydrogels slowly release rhIL-2 and maintain the rhIL-2 protein in an intact form that is both biologically and therapeutically active, which greatly enhances the clinical applicability of rhIL-2 immunotherapy [94].

Subcutaneous injection of a doxorubicin-loaded hydrogel composed of sugar beet pectin (SBP) associated with biodegradable gelatin (SBP/gelatin) successfully suppressed mouse MEL B16F1 cell tumor growth in nude mice [95].

The human MEL cell line Me665/2/21 derived from a cutaneous metastasis was treated for $48 \mathrm{~h}$ with a cisplatinloaded hydrogel and it showed similar and, in certain cases, higher cytotoxic activity towards the MEL cell line compared with free cisplatin at the same concentration [79].

A novel system for incorporating paclitaxel has been investigated to lower toxicity and improve efficacy [96]. Tumor activity upon using a paclitaxel (PTX) loaded hydrogel composed of a $\mathrm{pH}$ - and temperature-sensitive block copolymer, the poly(e-caprolactone-co-lactide)-poly(ethylene glycol)-poly( $\varepsilon$-caprolactone-co-lactide) (PCLA-PEGPCLA) block copolymer, was analyzed in vivo using B16F10 MEL cells. After 2 weeks of subcutaneously injecting the B16F10 MEL cells into male mice, the tumors were allowed to grow, and the results demonstrate that saline-treated mice produced a tumor volume of approximately $17 \mathrm{~cm}^{3}$, while the PTX-treated mice tumors were smaller than $7 \mathrm{~cm}^{3}$, which demonstrates that a PTX-loaded block copolymer hydrogel can effectively suppress tumor development [97].

2.2. Liposomes and Micelles. Recently, research has described the importance of lipids in drug carrier systems such as liposomes [98]. According to Fahy and coworkers (2005) [99], lipids are hydrophobic molecules that are soluble in organic solvents. However, certain lipids have amphiphilic characteristics due to both hydrophilic and hydrophobic segments [100]. These compounds can form carrier systems, such as micelles and liposomes, because they can selfassemble in the presence of water [101]. Micelles are formed when amphiphilic components concentration exceeds a certain threshold concentration. The micelles' size and shape depend on $\mathrm{pH}$, temperature, constituent geometry, and intermolecular interactions $[98,99,102,103]$.

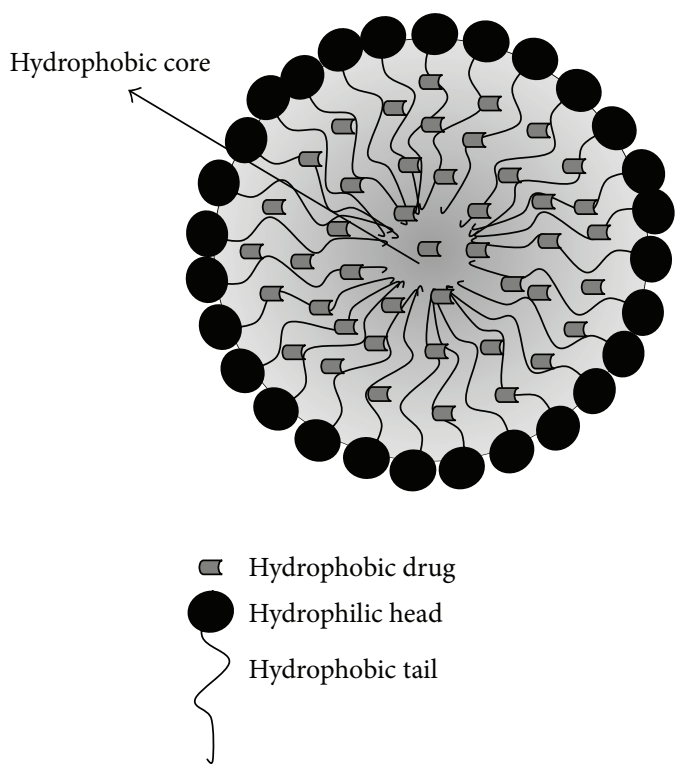

Figure 1: Micelle with hydrophobic compounds.

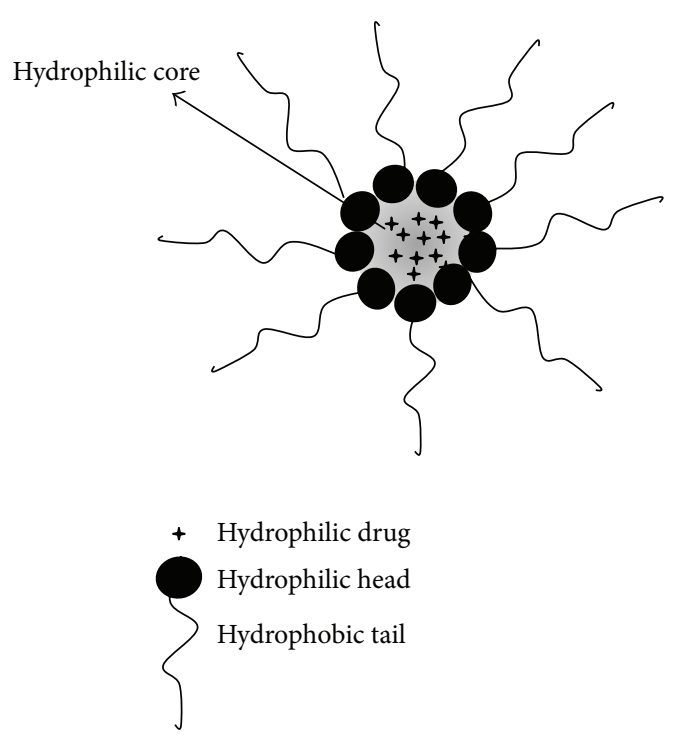

FIgURE 2: Micelle with hydrophilic compounds.

The liposomes are microscopic spherical nanostructured with a well-defined shape and size, which varies from $10 \mathrm{~nm}$ to several micrometers, depending on the technique used to create them [104]. These vesicles are formed by an external phase with double phospholipid membranes and an internal phase formed by an aqueous medium [105]. These components provide an amphiphilic character due to the organized double phospholipid layer that surrounds the aqueous compartment. Thus, they can encapsulate both hydrophobic and hydrophilic compounds [106, 107]. Figures 1, 2, and 3 schematically show the micelles and liposomes structures.

Liposomes have high versatility because they can be modified based on pharmacological and pharmaceutical needs. Thus, the size, surface, lamellarity, lipid composition, volume, 

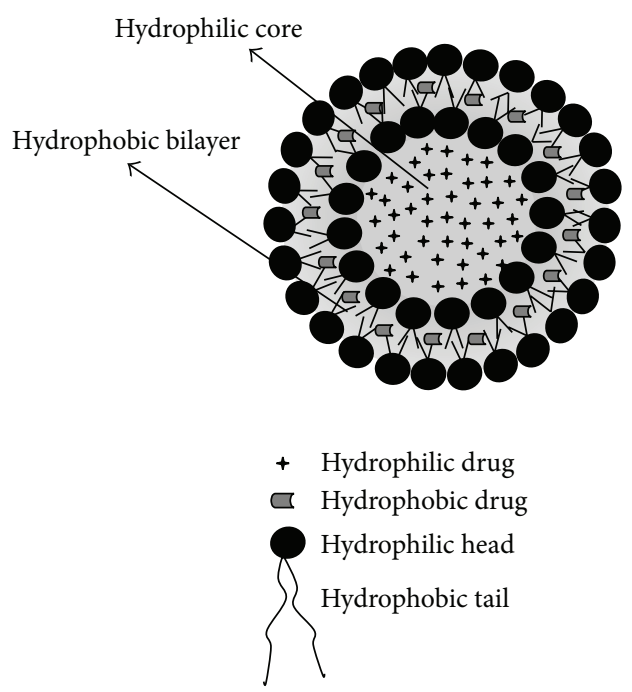

FIGURE 3: Liposome encapsulated hydrophobic and hydrophilic compounds.

and inner aqueous medium composition can be modified in these vesicles [108].

Liposomes can be formed with natural lipids, such as sphingomyelins, as well as lecithins and synthetic lipids, such as dimyristoyl, distearoyl, dipalmitoyl, and dioleoyl [109]. Currently, there are several methods to obtain liposomes. Under certain conditions, they can undergo spontaneous rearrangement and be derived from preformed micelles by changing the solution or applying external energy, such as by extrusion through filter membranes, sonication, or agitation $[98,110,111]$.

The extrusion technique forces a lipid suspension to pass through a polycarbonate membrane with a well-defined pore size [112]. This method can produce vesicles with a diameter near the membrane pore size used to prepare the liposomes. Over time, studies have shown several advantages from this technique; for example, the average size of the vesicles formed is reproducible due to the physical process involved in liposome formation, residual organic solvent removal at the end of the technique is unnecessary, and a large variety of lipids can be used to prepare the vesicles [111, 113, 114].

For the sonication technique, liposomes are prepared using a sonicator to mix the lipid suspension. The pressure exerted by the sonicator stirring causes a decrease in the larger vesicles sizes. Thus, the stirring time is decisive for liposome size formed. The main advantage of this technique is less time in liposome preparation $[111,115]$.

Liposomes have attracted the attention of the scientific community due to their high versatility. Liposomes have greater therapeutic efficacy than conventional pharmaceutical system because they promote slow drug release at the target site [107, 116, 117]. Furthermore, liposomes are less toxic, nonimmunogenic, and biocompatible with organic tissues. They can decrease systemic toxicity and improve drug efficacy, especially for antibiotics, antifungals, and anticancer drugs $[107,118,119]$. Thus, using liposomes as a delivery system for chemotherapeutic agents offers great prospects for cancer treatment [108].

Wolf et al. (2000) [120] incorporated the DNA repair enzyme, T4 endonuclease V, into liposomes composed of phosphatidylcholine, phosphatidylethanolamine, oleic acid, and cholesteryl hemisuccinate $(2: 2: 1: 5$ molar ratio) and applied it to human patients with a previous history of skin cancer after ultraviolet exposure. These liposomes were developed by encapsulating a purified recombinant $\mathrm{T} 4$ endonuclease $V$. The researchers observed that the enzyme was present in skin cells, which, in the skin, tends to improve DNA repair. Moreover, they reported that the T4 endonuclease $\mathrm{V}$ liposome prevented ultraviolet-induced upregulation of tumor necrosis factor-alpha and interleukin-10 mRNAs as well as interleukin-10 protein.

Another study using T4 endonuclease V in liposomes was conducted by Yarosh et al. (2001) [121]. They observed 30 patients with xeroderma pigmentosum in a double-blind study. The patients were randomly assigned to use either the T4N5 liposome or a placebo liposome lotion, daily for 1 year. To produce the $\mathrm{T} 4$ endonuclease $\mathrm{V}$ liposome lotion, they used $1 \mathrm{mg} / \mathrm{L} \mathrm{T} 4$ endonuclease $\mathrm{V}$ encapsulated in liposomes in a $1 \%$ hydrogel lotion. The placebo lotion was prepared with the same liposomes in a $1 \%$ hydrogel solution but without the enzyme T4 endonuclease V. Patients with xeroderma pigmentosum have a genetic error in a DNA repair enzyme. Thus, the incidence of skin cancer in these patients is more frequent than in other people. The researchers noted a decrease in the xeroderma pigmentosum incidence rate and skin cancer in the groups treated with the T4 endonuclease $\mathrm{V}$ liposome. Furthermore, no significant adverse effects were reported.

Pierre et al. (2001) [122] proposed a topical delivery system for 5-aminolevulinic acid (5-ALA) based on liposomes with a similar composition to the stratum corneum to treat skin cancer. They prepared these liposomes using a reverse phase evaporation technique and the following components: ceramide, cholesterol, palmitic acid, cholesteryl sulfate, and $\alpha$-tocopherol. 5-ALA is used in photodynamic, which had been shown effective in topical treatment for a variety of skin diseases. 5-ALA liposomal delivery system targeted and delivered 5 ALA to skin layers (viable epidermis and dermis) compared with the aqueous solutions typically applied in a 5ALA-PDT clinical procedure. Thus, liposomes were a suitable delivery system for 5 ALA.

Chen et al. (2012) [123] developed a transdermal drug delivery system for curcumin-loaded liposomes and investigated in vitro skin permeation and the antineoplastic effect in vivo. Soybean phospholipids, hydrogenated soybean phospholipids, and egg yolk phospholipids were used to obtain the liposomes. Curcumin-loaded liposomes composed of soybean phospholipids promoted greater in vitro drug permeation. Moreover, the liposomes were effective against MEL and the liposomes composed of soybean phospholipids showed a higher capacity to inhibit MEL cells growth.

Nobayashi et al. (2002) [124] evaluated the efficiency of cationic multilamellar liposome-mediated gene transfer in murine MEL cell lines and an experimental gene therapy for subcutaneous MEL. They used B16F10, which is a murine 
MEL cell line and cationic liposomes composed of $N-(\alpha-$ trimethylammonioacetyl)-didodecyl-D-glutamate chloride (TMAG), dilauroyl phosphatidylcholine (DLPC), and dioleoyl phosphatidylethanolamine (DOPE) at molar ratio $1: 2: 2$. They observed that repeated exposure to liposomes increased the transduction efficiency in murine MEL cells and experimental subcutaneous MEL tissue; thus, the therapy was effective for the intended purpose.

Liu and colleagues (2013) [125] developed liposomes with quercetin to improve its delivery into human skin and evaluate the potential anti-UVB effect. The liposomes were composed of soybean phosphatidylcholine, cholesterol, tween 80 , and span 20. The researchers prepared liposomes with high entrapment efficiencies and a prolonged drug release. The group yielded good results; the quercetin liposomes enhanced cell viability compared with a quercetin solution in UVB-irradiated HaCaT cells, the reactive oxygen species levels decreased, the edema and inflammation were alleviated and 3.8-fold more quercetin liposomes permeated the skin compared with quercetin solution.

2.3. Cyclodextrins. Cyclodextrins (CDs) are a family of natural cyclic oligosaccharides with $\alpha$-(1-4) linked glucopyranose subunits bonds [126-128]. They are produced from starch via enzymatic conversion using cyclodextrin glycosyl transferases (CGTases) $[129,130]$. CDs have received more attention as a pharmaceutical excipient, because they can form drug complexes [130-132]. Furthermore, CDs are biocompatible and can be used to reduce in vitro and in vivo toxicity and the delivery profile can be modulated with great flexibility by changing the guest components [133].

$\beta$-cyclodextrin ( $\beta \mathrm{CD})$ is a CD that comprises seven $\alpha$ $(1,4)$-linked $\alpha$-d-glucopyranose units and is used extensively due to its ready availability and because its cavity size is suitable for a varied drug range [131]. Many hydrophilic, hydrophobic, and ionic CD derivatives have been developed to increase CDs versatility and decrease undesirable drug properties $[134,135]$.

Recent studies have demonstrated that CDs are efficient drug delivery systems for targeting cancer cells [136-138]. A complex formed between $\mathrm{CD}$ and a gemini surfactant (CDgemini) was used to carry curcumin analogue, and the cytotoxic effect of this system in MEL cells was analyzed. The results indicate that the drug-loaded CDgemini showed higher caspase 3/7 activity levels compared with drugs dissolved in DMSO, which enhance their ability to trigger apoptosis. Further, the researchers demonstrated that this treatment was more specific for MEL cells than for healthy keratinocytes [139].

In general, the $\mathrm{pH}$ surrounding tumor tissues tends to be more acidic (i.e., 5.5 to 6.5) than normal tissue (i.e., 7.4) [140, 141]. Thus, $\mathrm{pH}$-triggered drug release systems are promising for intracellular delivery of anticancer drugs [142]. Certain substances exhibit $\mathrm{pH}$-sensitive host-guest interactions with cyclodextrin and may be used as $\mathrm{pH}$-triggered drug release systems [143]. He and coworkers (2013) [144] synthesized a $\mathrm{pH}$-responsive material through acetonating $\alpha$-CD for PTX delivery. Results from in vitro drug release studies show a more rapid release profile in $\mathrm{pH} 5.0$ buffer comparison with physiological conditions ( $\mathrm{pH}$ 7.4). Moreover, this system can be effectively internalized by tumor cells; it demonstrates a superior cytotoxic activity and a longer incubation time results in higher efficiency. In addition, treatment with PTX loaded pH-sensitive $\alpha$-CD inhibited tumor growth even at the lower PTX dose (1.1 mg/kg) [144].

Polypseudorotaxanes are inclusion complexes formed between cyclodextrins and linear macromolecules such as polymers [145]. Doxorubicin (DOX) loaded polypseudorotaxanes were developed by Chang and colleagues (2013) [146] and in vitro antitumor studies including cellular uptake and inhibition efficiency were analyzed for B16 MEL cells. The results indicate that doxorubicin-loaded polypseudorotaxanes inhibited MEL cells proliferation. The loaded doxorubicin showed slower endocytosis than doxorubicin hydrochloride, perhaps due to the larger system size. The cellular uptake of loaded doxorubicin was greater upon increasing the incubation time. Polypseudorotaxanes may be a promising carrier for DOX as antitumor MEL therapy.

4-Hydroxynonenal (4-HNE) is the end product of lipid peroxidation, which has been broadly used to inducer oxidative stress, and it produces a cytotoxic effect in cancer cells $[147,148]$. The 4 -HNE inclusion complex with the derivative $\beta \mathrm{CD}$ (PACM- $\beta \mathrm{CD}$ ) was developed by Pizzimenti and coworkers (2013) to enhance 4-HNE stability [149]. The results demonstrate that the inclusion complex HNE/PACM$\beta C D$ was stable and significantly reduced more viable cells among the several cell lines tested, including human MEL A375 cells, than untreated control cells and cells treated with $10 \mu \mathrm{M}$ free HNE.

Disrupting the lipid rafts' integrity, which are plasma membrane microdomains rich in cholesterol, may modify tumorigenic processes by altering the functionality of CD44, which is a cell surface receptor involved in cell migration and tumor metastasis [150, 151]. Murai and colleagues (2011) [152] showed that cholesterol reduction might be effective for preventing and treating malignant tumors progressions. Methyl- $\beta$-cyclodextrin (M $\beta C D$ ) forms soluble inclusion complexes with cholesterol and depletes cholesterol in plasma membranes [153]. A study conducted by Onodera et al. (2013) [154] investigated the potential of $\mathrm{M} \beta \mathrm{CD}$ to cause apoptotic cell-death in a highly pigmented human MEL cell line. The results demonstrate that $\mathrm{M} \beta \mathrm{CD}$ induced apoptosis through cholesterol depletion in lipid rafts, which activated caspase-3/7 and promoted cancer cell apoptosis. Thus, $\mathrm{M} \beta \mathrm{CD}$ provides a potential strategy for treating MEL via lipid rafts modulation.

Mazzaglia and coworkers (2013) [155] developed an amphiphilic cyclodextrin (ACD) system for incorporating porphyrin derivatives to improve their water solubility and their selectivity towards MEL cells. The complexes formed showed higher cytotoxic activity in MEL cells than the free porphyrin derivative in water; thus, apoptotic cell death was observed at lower concentrations, and both cell proliferation and changes in cellular morphology were inhibited.

Mistletoe extract is often used in complementary cancer therapy [156]; it has been shown to stimulate cytokine production, modify intracellular protein synthesis, induce cell necrosis, and inhibit tumor colonization [157]. Strüh 
et al. (2013) [158] solubilized mistletoe triterpenoids with cyclodextrins and observed lower tumor growth, tumor necrosis, apoptotic cells, and prolonged survival in mice. These results indicate that solubilized mistletoe triterpenoids enhanced the antitumor effect of mistletoe extract.

Betulin (BET) is found in Betula sp. and has been used to treat skin diseases due to its therapeutic properties, including antitumor activity $[159,160]$. Complexes formed between BET and a novel CD derivative, octakis-[6deoxy-6-(2-sulfanyl ethanesulfonate)]- $\gamma$-CD (GCDG) were developed, and in vitro and in vivo experimental animal model experiments were conducted to verify antineoplasic activity in system. The results showed that BET complexation with CD improved BET solubility, which was an important property for enhancing BET antitumor activity. Moreover, BET promoted a lower MEL size, which was attributed to its antiangiogenic effect [160].

Interleukin-2 (IL-2) promotes immune recognition of MEL, while sparing normal cells [161]. However, secretion of certain immunosuppressive factors, such as TGF- $\beta$ (transforming growth factor- $\beta$ ), can decrease ability of the immune system to identify the tumor as being composed of foreign cells [162]. A system composed of methacrylate-f-CD to solubilize the TGF- $\beta$ inhibitor and liposomes loaded with a biodegradable crosslinking polymer and IL-2 cytokine was developed to sustain cytokines release to the tumor microenvironment and induces antitumor immune responses in a B16/B6 mouse. The results show that the TGF- $\beta$ inhibitor and IL-2 reduced tumor growth. Furthermore, the natural killer cells' activity increased [163].

Cancer photodynamic therapy (PDT) combines a photosensitizer or photosensitizing drug with a specific type of light source to treat cancers [164]. A nontoxic carrier was prepared using 2-hydroxypropyl-cyclodextrins (hpCDs) and metallocomplex meso-tetrakis(4-sulfonatophenyl)porphyrin (ZnTPPS4) as the photosensitizer. The results demonstrate that low irradiation doses do not promote a substantial damaging effect on MEL cells, whereas higher irradiation doses induce cell death. Cell apoptosis or tissue necrosis depends on the radiation intensity. ZnTPPS4 complexation was an efficient sensitizer in human MEL cells [165].

2.4. Liquid Crystalline Phases. Pharmaceutical companies have shown an interest in developing nanostructured systems, such as liquid crystals, which have advantages that are mainly related to controlled drug release, and protect the active ingredients from thermal degradation or photobleaching $[166,167]$.

Liquid crystalline systems can compartmentalize drugs in the inner phase droplets, which have different physicochemical properties than the dispersing medium, and induce changes in the biological properties of the incorporated substances $[168,169]$.

Lehmann described an intermediate state in the thermal transformation from solid to liquid, which became known as liquid crystals (CLs) [170-172].

Liquid crystals are classified as lyotropic and thermotropic. When these systems are formed through adding solvents, they are lyotropic; thermotropic formation is

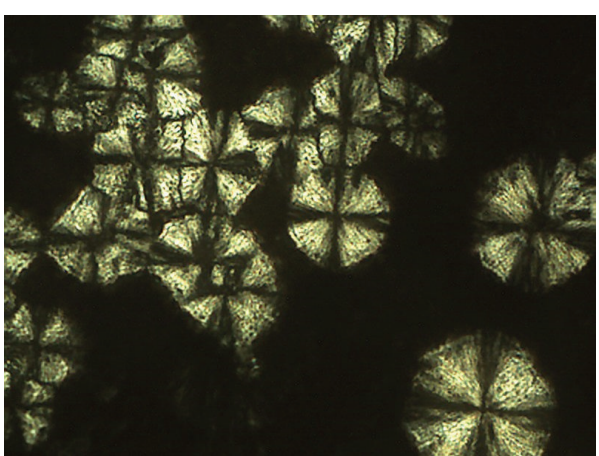

FIgURE 4: Polarized light microscopy of the lamellar phase (anisotropic system).

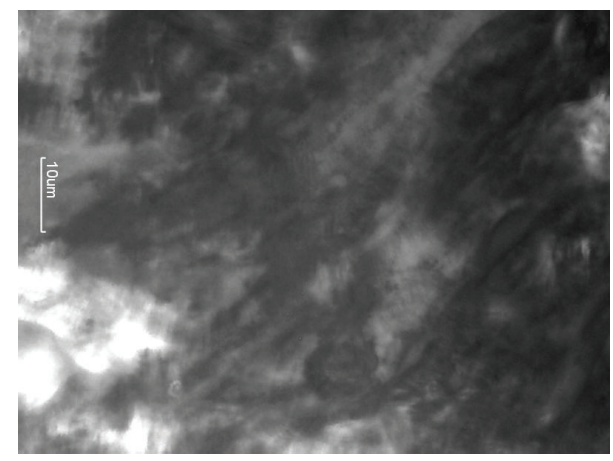

FIGURE 5: Polarized light microscopy of the hexagonal phase (anisotropic system).

temperature-dependent. As the surfactant concentration changes occur, different liquid-crystalline forms can be generated, such as lamellar, hexagonal (hexasomes), and cubic (cubosomes) forms. The lamellar phase is formed by parallel, planar layers of surfactant bilayers separated by a solvent layer, which form a one-dimensional network. Beginning in the hexagonal phase, aggregates are formed through an arrangement of long cylinders that form two-dimensional structures. In the cubic phase systems, the molecules are arranged in a three-dimensional system that consists of two corresponding water channel networks surrounded by lipid bilayers or surfactant [169].

Polarized light microscopy is an important tool to identify and classify liquid crystalline materials. Photomicrographs are used to demonstrate the observed textures, typically using polarized light [173]. Under polarized light plane, the sample is anisotropic if it can divert the plane of incident light that is isotropic and does not deflect light. The lamellar and hexagonal mesophases are anisotropic, while the cubic mesophase is isotropic $[169,174]$.

Figures 4 and 5 show microscopy systems in lamellar and hexagonal phases, respectively.

Liquid crystals have increasingly been used as delivery systems; Bitan-Cherbakovsky and colleagues (2013) [175] evaluated the release of gallic acid in cancer treatments. Liquid crystalline systems were studied as a dermal delivery system with ascorbyl palmitate to prevent skin aging [176]. 
Cubosomes present potential utility as a drug delivery system in skin cancer therapy, such as for MEL, due to their bioadhesion properties and enhancer penetration [177]. Bei and coworkers (2010) formulated dacarbazine-loaded cubosomes composed of glycerol monooleate RYLO MG 19 (GMO), poloxamer 407 (F127), phosphate buffer saline (PBS), and DTIC (5-(3, 3-dimethyl-1-triazeno) imidazole4-carboxamide) and characterized their physicochemical properties. Currently, dacarbazine is a first-line chemotherapy agent against MEL. Due to the material's bioadhesion properties, it presents a potential for use in MEL therapy [178].

5-FC phytanyl (5-FCPhy) is an amphiphile prodrug, carried in a lyotropic liquid crystalline system, and its in vivo efficacy as a chemotherapy agent against breast cancer has been investigated. The results show that the 5-FCPhy-loaded lyotropic liquid crystalline system reduced tumor size in a dose-dependent manner; the smallest average tumor volumes were observed with highest 5-FCPhy doses. Thus, a 5-FCPhyloaded lyotropic liquid crystalline system may be used as a controlled drug delivery system for chemotherapeutic treatments such as for MEL [179].

von Eckardstein et al. (2005) developed an intracavitary carrier system composed of cubosomes that encapsuled carboplatin and paclitaxel; the release kinetics, the antitumor activity against glioma, and the prolonged survival were analyzed. The results show a significantly smaller tumor in animals treated with paclitaxel/carboplastin compared with the control group although survival did not differ among the groups studied. Both the drugs carried in the crystalline cubic phases presented cytotoxic activity in tumor cells, which indicates that they play an important role in cancer therapy [180]. The same researchers clinically observed 12 patients with a recurrent glioblastoma multiforme, who received an intracavitary application of paclitaxel and carboplatin cubosomes in different doses. The results indicate that this system is feasible and safe [181].

Many studies show the advantages of liquid crystals as a drug delivery system. However, most studies conducted using liquid crystals as a chemotherapy drug delivery systems remain at an early development stage. Several studies have been executed to characterize certain systems without efficacy trials [178, 182-186]. However, more studies are necessary to better understand the role of liquid crystals as a drug delivery system in MEL therapy.

2.5. Nanoparticles. The Food and Drug Administration (FDA) defines a nanoparticle as any material with a dimensional range of approximately 1 to $100 \mathrm{~nm}$ or end products with a dimension up to $1 \mu \mathrm{m}$ that exhibit properties or biological phenomena (chemical, physical, and biological effects) [187-192]. Nanotechnology-based drug delivery systems have gained scientific notoriety due to variety of applications and many benefits; these systems may include polymeric and lipid-based nanoparticles.

In 1996, Müller and Lucks introduced the term solid lipid nanoparticle (SLN) to patent a manufacturing process using high pressure homogenization [193]. SLNs are the first generation of lipid nanoparticles (LN), which can be constructed by only using solid lipids (i.e., lipids that are solid at room temperature) [194].

Subsequent modifications to SLNs have been described, which are nanostructured lipid carriers (NLC) and are the second generation of LN [194]. Both SLN and NLC are constructed from lipid solid. However, they can be distinguished by their internal structures. The internal SLN structures only have solid lipids and NLCs are constructed using a blend of solid and liquid lipids, which produces imperfections in the crystal lattice $[195,196]$, as shown in Figure 6 . These imperfections have also been observed for SLNs because SLNs that contain multiple solid lipid components with distinct structural features may improve the drug entrapment efficiency [195, 197, 198].

In addition to $\mathrm{LN}$, polymeric nanoparticles (PN) may be constructed from organic polymers or inorganic materials, such as silica [199]. Polymers or lipids form solid NP nuclei, which promotes more stable systems, sustained drug release, and a uniform particle size distribution [200].

$\mathrm{PN}$ can be referred to as nanocapsules or nanospheres depending on their composition [166], as shown in Figure 7. The presence of oil promotes a vesicular structure in nanocapsules that forms reservoir-based drug delivery systems [201, 202], while nanospheres form matrix organized polymeric chains in the absence of oil $[203,204]$.

Drugs are entrapped in PN throughmixing the drug and polymer solution. Drug compounds are physically entrapped in the nanoparticle through polymer self-assembly [200]. PNs using different encapsulation mechanisms, such as dissolving it, disperse it or chemically adsorbs it in the constituents of the polymer matrix $[166,205,206]$.

Both types of nanoparticles (lipid and polymeric nanoparticles) can be used as a drug delivery system with antitumor properties in MEL therapy.

Identifying tumor microenvironment properties is critically important for accumulating the most nanoparticles at the site of action, which decreased drug toxicity and adverse effects. Pathological systems' metabolism, cell morphology, and microenvironment have peculiar characteristics [207]. Through knowing these characteristics, specific biomarkers (antibodies, aptamers, peptides, and small molecules) can be identified, and molecules can be attached to the nanoparticles surface for successful targeted drug delivery to the site of action $[208,209]$.

Nonspecific interactions may appear in addition to specific biomarkers such as van der Waals bonds and electrostatic and steric affinities that can be used to predict the propensity for nanoparticle adhesion and uptake [210]. Thus, the particular nanoparticles structural components (lipids, surfactants, and polymers: Table 1) may improve drug targeting to the tumor tissue [198, 211], prevent opsonization and a consequent decrease in nanoparticles degradation by the immune system [212-214], improve the interactions between the surface nanoparticles and tumor cell membrane [215-217], alter the normal function of organelles, and induce apoptosis, which would increase tissue-specific cytotoxicity in cancer cells $[197,218,219]$. 


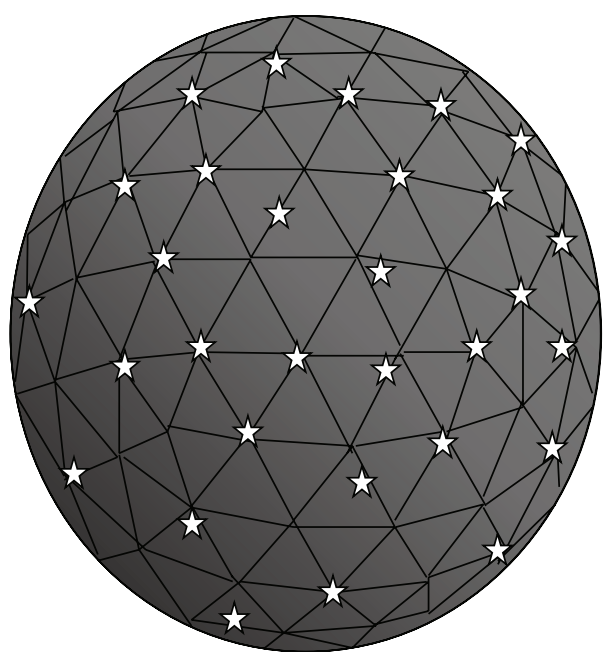

th Drug dissolved or dispersed Solid lipid

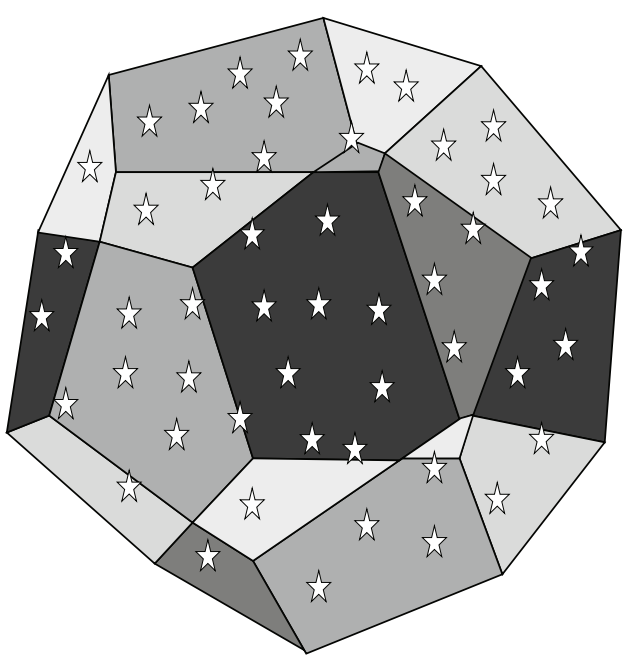

it Drug dissolved or dispersed

Blend of liquid and solid lipid or blend of solid lipids

(b)

FIGURE 6: The image shows an SLN-organized lipid matrix composed of only solid lipids (a) and imperfections in the crystal lattice (b) on NLC or SLN that are composed of multiple solid lipid components with distinct structural features that are distorted upon forming a perfect crystal.

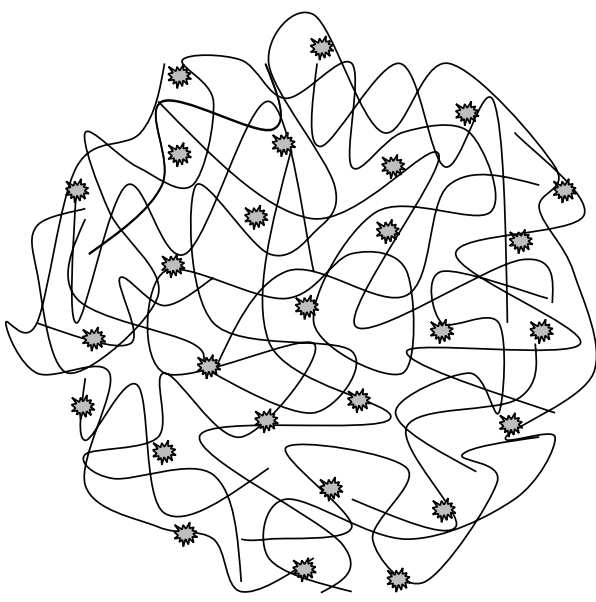

- Drug dispersed

\&o Polymeric structure

(a)

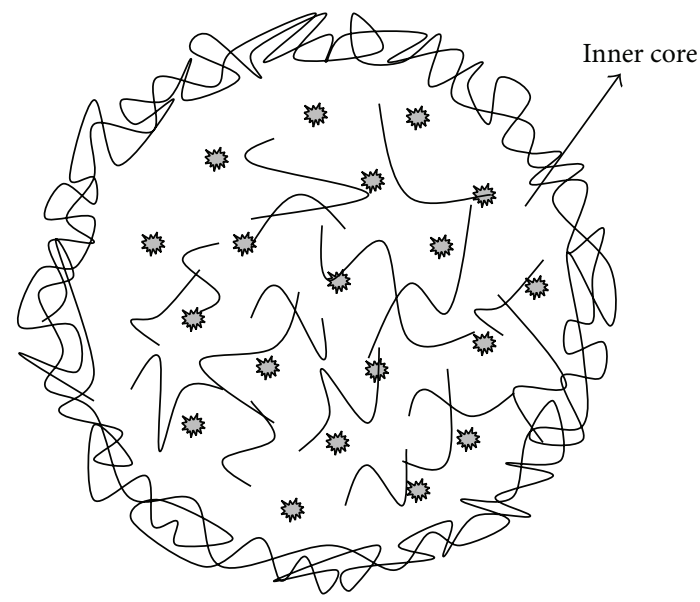

- Drug entrapment

\& Polymeric structure

(b)

FIgURE 7: Polymeric nanoparticles schematics: nanospheres (a) and nanocapsules (b).

2.5.1. Benefits of Using Nanoparticles for MEL-Targeted Drug Delivery. Recent studies have shown improved SLN uptake and accumulation in tumor tissue [220], due to physiological tumor tissue characteristics, such as abnormalities and a dysfunctional tumor vasculature, which allow SLN in the range $30-100 \mathrm{~nm}$ to easily permeate the tumor. Moreover, higher SLN concentrations are maintained in the tumor for long periods of time due to low venous return and lymphatic drainage [221-223].
$\mathrm{Xu}$ and coworkers (2009) development a docetaxelloaded SLN composed by egg phosphatidylcholine, dioleoylphosphatidylethanolamine, trimyristin, and lactobionic acid that showed 2.4-fold greater accumulation in tumors compared with the nonencapsulated drug 6 hours after intravenous administration. Galactosylation of the nanoparticle surfaces enhanced the cellular uptake of docetaxel and promoted passive targeting of the drug into the tumor cell, which reduced systemic toxicity [224]. 
TABLE 1: Particular nanocarrier structural components for improving drug targeting to the tumor tissue.

\begin{tabular}{ll}
$\begin{array}{l}\text { Components for successful } \\
\text { targeted drug delivery in } \\
\text { antitumor }\end{array}$ & Benefits in anticancer therapy \\
\hline & \multicolumn{1}{c}{ Active targeting } \\
& $\begin{array}{l}\text { Cancer cells take up 100-fold more low density lipoprotein (LDL) than normal } \\
\text { tissue due to upregulated LDL receptors in cancer cells for membrane synthesis } \\
\text { during cell division associated with malignant transformation processes. Thus, LDL } \\
\text { has been proposed as a drug carrier for anticancer agents. }\end{array}$ \\
$\begin{array}{l}\text { Cholesterol } \\
\text { P-linolenic acid; linoleic acid; } \\
\text { arachidonic acid; } \\
\text { eicosapentaenoic acid; and } \\
\text { docosahexaenoic acid). }\end{array}$ & $\begin{array}{l}\text { They can be attached to the tumor cell membrane more easily, which results in } \\
\text { disruption and fluidity of the cell membranes. Tumor progression is reduced by } \\
\text { modulating p53, p16, and p27 expression and cell cycle regulation, as well as by } \\
\text { inducing cell death by apoptosis and necrosis. }\end{array}$ \\
$\begin{array}{l}\text { Hyaluronic acid } \\
\text { Hyaluronic acid is an extracellular matrix compound that specifically binds CD44, } \\
\text { which is an extracellular membrane protein that regulates various cellular } \\
\text { responses. CD44 is overexpressed in cancer cells, while normal cells underexpress } \\
\text { this protein. Thus, CD44 is a good candidate biomarker for cancer cells. }\end{array}$ \\
$\begin{array}{l}\text { Folate is important for producing and maintaining new cells because it can } \\
\text { participate in nucleotide synthesis. Folates receptors are highly overexpressed in } \\
\text { cancer cells. In addition, only the malignant cells, not normal cells, transport } \\
\text { folate-conjugates; thus, the folate-drug conjugation can improve tumor-targeted } \\
\text { drug delivery. }\end{array}$
\end{tabular}

References

$[208,239-245]$

Passive targeting

Polysaccharides; polyacrylamide; polyvinyl alcohol; polyvinylpyrrolidone; PEG; PEG-containing copolymers (poloxamers; poloxamines; polysorbates; and PEG copolymer).

Cationic surfactants

They prevent the opsonin binding to the nanoparticle surfaces and, consequently, recognition as well as phagocytosis of the nanoparticles by the mononuclear phagocytic system, which enhances the blood circulation time.

$[212,255-258]$ surface.

Higher cationic nanoparticle uptake in HeLa cells compared with anionic nanoparticles was observed [225], which demonstrates that nanoparticle uptake is influenced by the nanoparticle surface molecules [226, 227].

Guo et al. (2010) investigated the antitumor effects of resveratrol (RES) bovine serum albumin nanoparticles. The results showed that the concentration of RES was greatly increased in the target tissue when the RES-loaded nanoparticle was injected. High levels of RES were observed in bloodstream for long periods of time after the RES suspension was administered (nonencapsulated RES), which illustrated incomplete RES distribution. Moreover, the results show that RES-loaded nanoparticles promoted greater tumor growth inhibition [228]. Teskač and Kristl (2010) showed that where NLC (Compritol 888ATO and Phospolipon $80 \mathrm{H}$ as the oil phase and Lutrol as the steric stabilizer) was used to incorporate RES, it crossed the cell membrane, was delivered throughout the cytosol, and was located in the perinuclear region without inducing cytotoxicity. They found that RES solubility, stability, and intracellular release were also enhanced in the RES-loaded nanoparticle [229].
The drug release profile was modulated using drugloaded LN. A recent study demonstrates that the camptothecin release rate can be modified by changing lipid nanoparticle inner phases. The SLN composed of precirol as the solid lipid showed the most sustained release $(45 \%$ of the total drug was released after 30 hours) while the NLC composed of precirol as the solid lipid and squalene as the liquid lipid showed more rapid release (65\% of the total drug was released after 30 hours). Drug mobility decreased when solid or crystalline substances were incorporated into the nanoparticles, which decreased the drug levels released as a function of time. Greater inhibition of MEL cell proliferation was observed when the cells were treated with nanoparticles, which may be because MEL cells exhibit excellent uptake endocytosis [230].

Docetaxel-loaded NLC (DTX-NLC) composed of stearic acid, glyceryl monostearate, soya lecithin, and oleic acid showed as sustained-release drug profile (77\% of the total drug after 24 hours), while Duopafei (docetaxel injection provided by Qilu Pharmaceutical Co., Ltd. in China) showed $100 \%$ release after 24 hours. In addition, DTX-NLC showed greater cytotoxicity against MEL cells compared with 
Duopafei through enhanced apoptosis. Moreover, DTX-NLC showed low cytotoxicity for healthy cells because the drug is only released after endocytosis by a target cell [231].

Camptothecin was encapsulated into NLC, which was composed of cetyl palmitate, coconut oil, and Myverol associated with a quantum dot (metallic compounds at the core of the semiconductor NLC) as oil phase and Pluronic 68 solution as water phase. Camptothecin-loaded NLC presented superior cytotoxicity against MEL cells and the greater cell uptake compared with other carriers. Cellular endocytosis was essential for cell viability and the quantum dots showed a minimal capacity to influence proliferation. In addition, camptothecin accumulation in the MEL increased by approximately 6.4-fold following administration of the camptothecin-loaded nanoparticle. In vivo real-time monitoring showed that a camptothecin-loaded nanoparticle associated with a quantum dot was strongly localized at tumors with a persistent signal for 24 hours. The drug-loaded NLC was directed using quantum dot to efficiently transmit sustained tumor bioimaging, in addition to promoting drug release. This system offers the potential for diagnosing or monitoring evolution of the tumor through bioimaging and for drug delivery through nanocarrier [232].

Multiple synthetic and natural biodegradable polymers may be used in antitumor drug delivery systems, such as polyesters (e.g., polylactic acid, PLA), polyamino acids (e.g., polyaspartic acid), and polyoxypropylenes (e.g., poloxamers) [233].

Interleukin-2 was delivered by a polymeric nanoparticle composed of a low molecular weight polyethylenimine linked by $\beta$-cyclodextrin and conjugated with folate; this molecule was analyzed as a potential MEL antitumor therapy. High levels of tumor suppression were observed after peritumoral injection of the polymeric nanoparticle with interleukin-2, which prolonged survival in mice; thus, it is a promising genebased therapeutic strategy for MEL. The antitumor effect can be attributed mainly to activation, proliferation, and infiltration of effector T cells and NK cells into the tumor; the therapeutic efficiency was dose-dependent and presented low cytotoxicity [234].

Polymeric nanoparticle using polylactic-co-glycolic acid (PLGA) as a polymer to incorporate coumarin increased the cellular uptake rate 2 -fold versus nonencapsulated coumarin. In addition, molecular signals for mRNA expression were used to demonstrate that the coumarin-loaded nanoparticle downregulated cyclin-D1, proliferating cell nuclear antigen (PCNA), survivin, and Stat-3, and it upregulated p53 and caspase-3, promoting enhanced apoptosis of MEL tumor cells compared with nonencapsulated coumarin [235].

As a drug delivery system for apigenin, PLGA-PN promotes faster mobility and site-specific activity in MEL in addition to efficiently preserving apigenin photodegradation. The results also showed increased free radical accumulation and antioxidant enzymes depletion inside tumor cells, which exacerbated DNA damage and results in apoptosis through mitochondrial dysfunction [236].

A polymer-based delivery vehicle for cisplatin composed of chitosan and carboxymethylcellulose showed enhanced cytotoxicity (approximately 10-fold greater) in MEL tumor cells compared with nonencapsulated cisplatin. Further, rapid intracellular drug release was observed upon endocytosis of this system by a tumor cell, and only high-density NPs and positively charged-surfaces were capable of releasing cisplatin into MEL. Moreover, it decreased drug loss during blood circulation [237].

Superparamagnetic iron oxide nanoparticles consist of a carboxydextran shell and show increased uptake in human mesenchymal stem cells; the nanoparticle uptake efficiency was related to a higher density of carboxyl groups on the nanoparticle surface [238].

\section{Advantages and Disadvantages of Nanocarrier Systems}

This paper describes umpteen benefits to use nanocarriers system to vehiculate drugs used in melanoma therapy. But, to choose the better system type, it is also necessary to analyze the disadvantage of each system. Table 2 describes main advantages and disadvantages of each system.

\section{Nanocarriers Application in Animal Model or Clinical Studies}

Particular nanocarrier structural components were previously described for improving drug targeting to the tumor tissue (Table 1). Now, some animal models studies or clinical efficacy will be portrayed.

A study realized by Shi and coworkers (2014) demonstrated that microRNA-34a and paclitaxel-loaded functional cationic solid lipid nanoparticles presented a synergistic anticancer efficacy. In vivo test was conducted and this system was much more potent inhibitor of B16F10-bearing tumor growth and can eliminate melanoma metastasized to the lungs cells compared to single drug-loaded SLN [273].

C57BL/6 mice were inoculated subcutaneously with B16F10 melanoma cells $\left(1 \times 10^{6}\right.$ in $100 \mu \mathrm{L} /$ animal $)$ to verify the effect of free curcumin (CUR) and CUR-loaded nanocapsules on melanoma tumor growth. Results showed that treatments significantly inhibited the tumor growth, 59.6\% $\left(1128.4 \mathrm{~mm}^{3}\right.$ tumor volume) after treatment with free curcumin, $61.4 \%$ $\left(1078.2 \mathrm{~mm}^{3}\right.$ tumor volume) after treatment with Curloaded lipid nanocapsule suspensions, and 71.3\% $\left(801.4 \mathrm{~mm}^{3}\right.$ tumor volume) after treatment with Cur-loaded polymeric nanocapsule suspensions, when compared to the control group treated with cell culture medium only $\left(2791.0 \mathrm{~mm}^{3}\right.$ tumor volume). Cisplatin was used as positive control and decreased $72.4 \%\left(770.0 \mathrm{~mm}^{3}\right)$ of tumor volume [274].

Interleukin-2-loaded polymeric nanoparticle inhibited the tumor growth and can lengthen survival in mice B16F1bearing melanoma. The antitumor effect was dose-dependent and the system demonstrated low toxicity, representing a new strategy in drug delivery system for melanoma gene therapy [234].

Cai et al., 2012, carried out a study to verify the influence of tumor-targeting nanocarrier in long-circulation effects promoted by PEGylated liposome. Results demonstrated that paclitaxel-loaded targeted PEGylated liposomes (TL-PTX) 
TABle 2: Main advantages and disadvantages of each system.

\begin{tabular}{|c|c|c|c|}
\hline Nanocarrier & Advantages & Disadvantages & References \\
\hline Hydrogels & $\begin{array}{l}\text { Cells and fragile drugs, like peptides, proteins, } \\
\text { DNA, and oligonucleotides, could be protected } \\
\text { by aqueous environment } \\
\text { Good transport of nutrients to cells and } \\
\text { products from cells } \\
\text { Cell adhesion ligands easily modified them } \\
\text { Can be injected as a liquid at body temperature; } \\
\text { Usually biocompatible }\end{array}$ & $\begin{array}{l}\text { Can be difficult to manufacture } \\
\text { Usually mechanically weak } \\
\text { Difficulty in encapsulating the drug } \\
\text { Problems connecting with the cells } \\
\text { Difficult to sterilize }\end{array}$ & {$[262]$} \\
\hline Liposomes & $\begin{array}{l}\text { They can be formed by natural or synthetic } \\
\text { lipids } \\
\text { Biodegradable } \\
\text { Nontoxic } \\
\text { Thermosensitive } \\
\text { Hydrophilic and lipophilic molecules can be } \\
\text { incorporated }\end{array}$ & $\begin{array}{l}\text { High-energy sonication frequently causes } \\
\text { oxidation and degradation of } \\
\text { phospholipid } \\
\text { Low-energy sonication requires long } \\
\text { periods of sonication and can also be } \\
\text { destructive to phospholipid } \\
\text { High-pressure homogenization can } \\
\text { confer decreased stability } \\
\text { Application of volatile organic solvents }\end{array}$ & [263-266] \\
\hline Micelles & $\begin{array}{l}\text { Ease to prepare } \\
\text { Good stability } \\
\text { Many administration routes available }\end{array}$ & Risk of disintegration after administration & [267] \\
\hline Cyclodextrins & $\begin{array}{l}\text { Potential solubilizing and stabilizing agents } \\
\text { Higher order complexes are possible } \\
\text { Targeting water-insoluble drugs to the oral } \\
\text { route }\end{array}$ & $\begin{array}{l}\text { Some cyclodextrins have been shown to } \\
\text { be irritants } \\
\text { Safety concerns limited their use for } \\
\text { parenteral administration }\end{array}$ & {$[268,269]$} \\
\hline Liquid crystals & $\begin{array}{l}\text { They are easy to prepare } \\
\text { Thermodynamically stable } \\
\text { Composed of simple chemicals } \\
\text { In situ phase transformations }\end{array}$ & $\begin{array}{l}\text { Difficult to prepare and administer due to } \\
\text { high viscosity } \\
\text { Toxicity related to high surfactant } \\
\text { concentration }\end{array}$ & {$[267,270,271]$} \\
\hline Nanoparticles & $\begin{array}{l}\text { They can be prepared by different methods } \\
\text { Hydrophilic and lipophilic molecules can be } \\
\text { incorporated } \\
\text { They can change the surface } \\
\text { Increased drug stability } \\
\text { Possibility of controlled drug release and drug } \\
\text { targeting }\end{array}$ & $\begin{array}{l}\text { Toxicological assessment is uncompleted } \\
\text { Low drug-loading capacities } \\
\text { It is difficult to develop an analytical } \\
\text { method for drug delivery } \\
\text { Difficult to scale up the production } \\
\text { Stability problems during storage }\end{array}$ & {$[195,272]$} \\
\hline
\end{tabular}

lengthen the half-life of paclitaxel 2.01-fold of conventional liposome and 3.40-fold of free paclitaxel in plasma. Higher accumulation of TL-PTX in tumor tissue, liver, and spleen was observed compared to conventional liposome and free paclitaxel [275].

Doxil, the first FDA-approved nanodrug [276], is corroborated to development of nanomedicine for melanoma therapy. After that, a lot of clinical trials have been done to verify the efficacy of nanodrugs to improve the survival and quality life in patients with melanoma, especially with poor prognosis [277].

In a clinical phase II study, Ugurel et al. (2004) verified that patients treated with liposomal doxorubicin as monotherapy present survival benefit. Outpatients setting (30 patients) were included on this study. Liposomal doxorubicin is used at $50 \mathrm{mg} / \mathrm{m}^{2}$ i.v. on days $1,22,43$ and 64 , subsequently at $40 \mathrm{mg} / \mathrm{m}^{2}$ at day 85 before first staging and in 4 -week intervals thereafter. The results demonstrated that 7 patients stay alive more than 300 days and 5 patients more than 400 days [278].
Patients with cancer stage IV melanoma participated in an open-label, phase II study conducted by Hwu and coworkers (2006). Patients received a combination of $75 \mathrm{mg} / \mathrm{m}^{2}$ per day of temozolomide, during 6 weeks, there was a 2 -week break between cycles, and they were continuously subcutaneously administrated PEGylated IFN-2b at $0.5 \mathrm{~g} / \mathrm{kg} /$ week. Results showed that patient's median survival was 12 months and they were followed for 16 months and brain metastases were developed in any patients. Researchers concluded that a combination therapy promotes antitumor activity in metastatic melanoma [279].

\section{New Approaches and Challenges}

The wide range of compositions, morphologies, and particle sizes exhibited by drug delivery systems makes it difficult to understand their cellular uptake mechanisms. Thus, elucidating fundamental cellular processes that cells used to import and export select extracellular molecules may contribute to understanding the cellular internalization mechanisms of the systems and aid in selecting the appropriate system to 
transport active compounds [280]. Endocytosis of particles into cells depends not only on particle size, but also on surface coating and cell type [226, 227, 238].

Advances in nanotechnology based drug delivery systems have improved our understanding of the biological effects of nanotechnology-based systems, which will undoubtedly lead to important, clinically relevant improvements in drug delivery. New challenges in developing nanotechnologybased drug delivery systems for MEL antitumoral therapy include the feasibility of upscaling processes to quickly bring the innovative therapeutic techniques to the market and the potential for multifunctional systems that will fulfill several biological and therapeutic requirements, such as the system needing to be able to target tumor cells or tumor environment after systemic delivery. Further challenges include researches on efficiency of targeted anticancer therapies and imaging agents as well as international standards regarding their toxicology and biocompatibility.

So, the possibility of nanocarriers can promote the targeted cancer therapy and potentially early detection of cancer lesions; noninvasive imaging that permits determination of molecular signatures induces the concept of personalized medicine [281]. But not only that, the personalized medicine based on adjusted therapy to individual differences that can be detected by genetic test, guiding the choose of drug and their dosage. So, combining clinical and molecular biomarkers in nanomedicine contribute to improvement of the disease management [282].

\section{Author's Opinion}

Drug delivery systems represent an alternative strategy to carrier antineoplastic agents. Many advantages of drug delivery system have been described in recent studies such as better drug stability, better bioavailability, controlled drug release, long circulation time in blood, selective organs or tissue distribution, a reduction of the total dose required, and minimizing the toxic side effects.

Certain drug delivery characteristic can distinguish their application such as hydrogel that are stimuli-sensitive swelling-controlled release system. Liposome can encapsulate both hydrophobic and hydrophilic compounds. CD can form drug complexes and are biocompatible. LC protects the active ingredients from thermal degradation or photobleaching. SLN and NLC are maintained in the tumor for long period of the time due to low venous return and lymphatic drainage. PN forms reservoir-based drug delivery systems in nanocapsules and matrix organized polymeric chains in nanospheres. The wide range of compositions, morphologies, and particle sizes exhibited by drug delivery systems makes it variable mechanism for successful targeted delivery, while making it difficult to understand their cellular uptake mechanisms.

Another important aspect is identifying pathological systems' metabolism, tumor cell morphology, and microenvironment properties for accumulating the most drug delivery system at the site of action, at which decreased drug toxicity and adverse effects and biomarkers (antibodies, aptamers, peptides, and small molecules) can be identified, and molecules can be attached to the systems surface for successful targeted drug delivery to the site of action.

Thus, elucidating fundamental cellular processes that cells used to import and export select extracellular molecules may contribute to understanding the cellular internalization mechanisms of the systems and aid in selecting the appropriate system to transport active compounds. Endocytosis of particles into cells depends not only on particle size, but also on surface coating and cell type.

Several studies on cancer have been conducted worldwide, but peculiarities of tumor cells that distinguish them from normal cells are not completely elucidated, which made the delineation of targeted drug delivery for cancer therapy difficult.

Another problem is that chemotherapy drug delivery systems remain at an early development stage. Several studies have been executed to physicochemically characterize certain systems. However, the influence of systems to improve drug biological properties is understudied.

Tumor microenvironment plays an important role in tumorigenesis and may also influence the success rate of melanoma therapy. The drug delivery systems need to cross anatomical and physiological barriers of tumor microenvironment. However, many mysteries emphasize the complexity of the task.

In the recent decade, one of the most studied fields is nanotechnology-based drug delivery and various targeting mechanisms were discovered such as cancer-specific ligand for receptor-mediated active targeting (i.e., folate and hyaluronic acid); microenvironment-responsive molecules that respond to changes in $\mathrm{pH}$, temperature, light, chemicals, and electromagnetic fields; PEGylation-induced passive targeting; electrostatics interaction and molecules that prevent the opsonization.

Drug delivery system for melanoma therapy may target the several pathways involved in melanoma development such as three-tiered Ras/Raf/MEK mitogen-activated protein kinase (MAPK); PI(3)K; NF-kappaB; p16INK4a/RB and ARF signalling pathways.

Although breakthrough in melanoma antitumor therapy research has been observed, more studies are necessary to better understand the role of drug delivery system in MEL therapy.

\section{Conflict of Interests}

The authors declare that there is no conflict of interests regarding the publication of this paper.

\section{Acknowledgments}

This work was supported by Coordenação de Aperfeiçoamento de Pessoal de Nível Superior (CAPES), Fundação de Amparo à Pesquisa do Estado de São Paulo (FAPESP), Conselho Nacional de Desenvolvimento Científico e Tecnológico ( $\mathrm{CNPq})$, and Programa de Apoio ao Desenvolvimento Científico da Faculdade de Ciências Farmacêuticas (PADC-FCF-UNESP). 


\section{References}

[1] H. J. Cohen, E. Cox, K. Manton, and M. Woodbury, "Malignant melanoma in the elderly," Journal of Clinical Oncology, vol. 5, no. 1, pp. 100-106, 1987.

[2] P. E. LeBoit, Pathology \& Genetics: Skin Tumours, edited by: World Health Organization, IARC Press, Lyon, France, 2006.

[3] R. N. Saladi and A. N. Persaud, "The causes of skin cancer: a comprehensive review," Drugs of Today, vol. 41, no. 1, pp. 37-53, 2005.

[4] E. de Vries, F. I. Bray, J. W. W. Coebergh, and D. M. Parkin, "Changing epidemiology of malignant cutaneous melanoma in Europe 1953-1997: rising trends in incidence and mortality but recent stabilizations in western Europe and decreases in Scandinavia," International Journal of Cancer, vol. 107, no. 1, pp. 119-126, 2003.

[5] J. Ferlay, H.-R. Shin, F. Bray, D. Forman, C. Mathers, and D. M. Parkin, "Estimates of worldwide burden of cancer in 2008: GLOBOCAN 2008," International Journal of Cancer, vol. 127, no. 12, pp. 2893-2917, 2010.

[6] A. Jemal, F. Bray, M. M. Center, J. Ferlay, E. Ward, and D. Forman, "Global cancer statistics," CA Cancer Journal for Clinicians, vol. 61, no. 2, pp. 69-90, 2011.

[7] R. Colombari, F. Bonetti, G. Zamboni et al., "Distribution of melanoma specific antibody (HMB-45) in benign and malignant melanocytic tumours. An immunohistochemical study on paraffin sections," Virchows Archiv A, vol. 413, no. 1, pp. 17-24, 1988.

[8] K. Blessing, D. S. A. Sanders, and J. J. H. Grant, "Comparison of immunohistochemical staining of the novel antibody melanA with S100 protein and HMB-45 in malignant melanoma and melanoma variants," Histopathology, vol. 32, no. 2, pp. 139-146, 1998.

[9] T. Gambichler, P. Regeniter, F. G. Bechara et al., "Characterization of benign and malignant melanocytic skin lesions using optical coherence tomography in vivo," Journal of the American Academy of Dermatology, vol. 57, no. 4, pp. 629-637, 2007.

[10] R. Harson and C. Grose, "Egress of varicella-zoster virus from the melanoma cell: a tropism for the melanocyte," Journal of Virology, vol. 69, no. 8, pp. 4994-5010, 1995.

[11] A. Ingraffea, "Melanoma," Facial Plastic Surgery Clinics of North America, vol. 21, no. 1, pp. 33-42, 2013.

[12] J. Y. Lin and D. E. Fisher, "Melanocyte biology and skin pigmentation," Nature, vol. 445, no. 7130, pp. 843-850, 2007.

[13] Y. Yamaguchi and V. J. Hearing, "Physiological factors that regulate skin pigmentation," BioFactors, vol. 35, no. 2, pp. 193199, 2009.

[14] S. L. Winsey, N. A. Haldar, H. P. Marsh et al., "A variant within the DNA repair gene XRCC3 is associated with the development of melanoma skin cancer," Cancer Research, vol. 60, no. 20, pp. 5612-5616, 2000.

[15] D. B. McKenna, V. R. Doherty, K. M. Mclaren, and J. A. A. Hunter, "Malignant melanoma and lymphoproliferative malignancy: is there a shared aetiology?" British Journal of Dermatology, vol. 143, no. 1, pp. 171-173, 2000.

[16] V. Bataille, "Genetic epidemiology of melanoma," European Journal of Cancer, vol. 39, no. 10, pp. 1341-1347, 2003.

[17] M. S. Brose, P. Volpe, M. Feldman et al., "BRAF and RAS mutations in human lung cancer and melanoma," Cancer Research, vol. 62, no. 23, pp. 6997-7000, 2002.
[18] K. Omholt, S. Karsberg, A. Platz, L. Kanter, U. Ringborg, and J. Hansson, "Screening of N-ras codon 61 mutations in paired primary and metastatic cutaneous melanomas: mutations occur early and persist throughout tumor progression," Clinical Cancer Research, vol. 8, no. 11, pp. 3468-3474, 2002.

[19] M. A. Tucker and A. M. Goldstein, "Melanoma etiology: where are we?” Oncogene, vol. 22, no. 20, pp. 3042-3052, 2003.

[20] M.-F. Demierre and V. K. Sondak, "Cutaneous melanoma: pathogenesis and rationale for chemoprevention," Critical Reviews in Oncology/Hematology, vol. 53, no. 3, pp. 225-239, 2005.

[21] K. Colston, M. J. Colston, and D. Feldman, "1,25dihydroxyvitamin D3 and malignant melanoma: the presence of receptors and inhibition of cell growth in culture," Endocrinology, vol. 108, no. 3, pp. 1083-1086, 1981.

[22] D. E. Godar, R. J. Landry, and A. D. Lucas, "Increased UVA exposures and decreased cutaneous Vitamin $\mathrm{D}_{3}$ levels may be responsible for the increasing incidence of melanoma," Medical Hypotheses, vol. 72, no. 4, pp. 434-443, 2009.

[23] S. V. Madhunapantula and G. P. Robertson, "Chemoprevention of Melanoma," Advances in Pharmacology, vol. 65, pp. 361-398, 2012.

[24] D. C. Whiteman, P. Watt, D. M. Purdie, M. C. Hughes, N. K. Hayward, and A. C. Green, "Melanocytic nevi, solar keratoses, and divergent pathways to cutaneous melanoma," Journal of the National Cancer Institute, vol. 95, no. 11, pp. 806-812, 2003.

[25] M. Megahed, M. Schön, D. Selimovic, and M. P. Schön, "Reliability of diagnosis of melanoma in situ," The Lancet, vol. 359, no. 9321, pp. 1921-1922, 2002.

[26] G. Massi and P. E. Leboit, "Melanoma in situ," in Histological Diagnosis of Nevi and Melanoma, pp. 403-412, Springer, 2004.

[27] W. H. Clark Jr. and M. C. Mihm Jr., "Lentigo maligna and lentigo-maligna melanoma," American Journal of Pathology, vol. 55, no. 1, pp. 39-67, 1969.

[28] V. Cardile, G. Malaponte, C. Loreto et al., "Raf kinase inhibitor protein (RKIP) and phospho-RKIP expression in melanomas," Acta Histochemica, vol. 115, no. 8, pp. 795-802, 2013.

[29] R. T. Prehn, “The paradoxical association of regression with a poor prognosis in melanoma contrasted with a good prognosis in keratoacanthoma," Cancer Research, vol. 56, no. 5, pp. 937940, 1996.

[30] S. M. Swetter, P. M. Ecker, D. L. Johnson, and J. D. Harvell, "Primary dermal melanoma: a distinct subtype of melanoma," Archives of Dermatology, vol. 140, no. 1, pp. 99-103, 2004.

[31] K. Hoek, D. L. Rimm, K. R. Williams et al., "Expression profiling reveals novel pathways in the transformation of melanocytes to melanomas," Cancer Research, vol. 64, no. 15, pp. 5270-5282, 2004.

[32] D. Grossman and D. C. Altieri, "Drug resistance in melanoma: mechanisms, apoptosis, and new potential therapeutic targets," Cancer and Metastasis Reviews, vol. 20, no. 1-2, pp. 3-11, 2001.

[33] M. Karin and A. Lin, "NF- $\kappa$ B at the crossroads of life and death," Nature Immunology, vol. 3, no. 3, pp. 221-227, 2002.

[34] L. A. Fecher, S. D. Cummings, M. J. Keefe, and R. M. Alani, "Toward a molecular classification of melanoma," Journal of Clinical Oncology, vol. 25, no. 12, pp. 1606-1620, 2007.

[35] L. M. Cohen, "Lentigo maligna and lentigo maligna melanoma," Journal of the American Academy of Dermatology, vol. 33, no. 6, pp. 923-939, 1995.

[36] S. Menzies, "Superficial spreading melanoma," in An Atlas of Dermoscopy, J. M. Ashfaq, A. Marghoob, and R. Marghoob, Eds., pp. 203-209, CRC Press, 2004. 
[37] A. E. Chang, L. H. Karnell, and H. R. Menck, "The national cancer data base report on cutaneous and noncutaneous melanoma: a summary of 84,836 cases from the past decade," Cancer, vol. 83, no. 8, pp. 1664-1678, 1998.

[38] E. T. Krementz, R. J. Reed, and W. P. Coleman III, "Acral lentiginous melanoma. A clinicopathologic entity," Annals of Surgery, vol. 195, no. 5, pp. 632-645, 1982.

[39] R. A. Scolyer, G. V. Long, and J. F. Thompson, "Evolving concepts in melanoma classification and their relevance to multidisciplinary melanoma patient care," Molecular Oncology, vol. 5, no. 2, pp. 124-136, 2011.

[40] N. J. Crowley and H. F. Seigler, "Late recurrence of malignant melanoma: analysis of 168 patients," Annals of Surgery, vol. 212, no. 2, pp. 173-177, 1990.

[41] M.-H. Schmid-Wendtner, J. Baumert, M. Schmidt et al., "Late metastases of cutaneous melanoma: an analysis of 31 patients," Journal of the American Academy of Dermatology, vol. 43, no. 4, pp. 605-609, 2000.

[42] A. J. Sober and J. M. Burstein, "Precursors to skin cancer," Cancer, vol. 75, no. 2, supplement, pp. 645-650, 1995.

[43] K. Hoffmann, J. Jung, S. El Gammal, and P. Altmeyer, "Malignant melanoma in 20-MHz B scan sonography," Dermatology, vol. 185, no. 1, pp. 49-55, 1992.

[44] T. S. Wang, T. M. Johnson, P. N. Cascade, B. G. Redman, V. K. Sondak, and J. L. Schwartz, "Evaluation of staging chest radiographs and serum lactate dehydrogenase for localized melanoma," Journal of the American Academy of Dermatology, vol. 51, no. 3, pp. 399-405, 2004.

[45] C. M. Balch, A. C. Buzaid, S.-J. Soong et al., "Final version of the American Joint Committee on Cancer staging system for cutaneous melanoma," Journal of Clinical Oncology, vol. 19, no. 16, pp. 3635-3648, 2001.

[46] S. B. Revin and S. A. John, "Electrochemical marker for metastatic malignant melanoma based on the determination of 1-dopa/l-tyrosine ratio," Sensors and Actuators B: Chemical, vol. 188, pp. 1026-1032, 2013.

[47] D. S. Tyler, M. Onaitis, A. Kherani et al., "Positron emission tomography scanning in malignant melanoma: clinical utility in patients with Stage III disease," Cancer, vol. 89, no. 5, pp. 1019$1025,2000$.

[48] D. A. Sipkins, D. A. Cheresh, M. R. Kazemi, L. M. Nevin, M. D. Bednarski, and K. C. P. Li, "Detection of tumor angiogenesis in vivo by $\alpha_{v} \beta_{3}$-targeted magnetic resonance imaging," Nature Medicine, vol. 4, no. 5, pp. 623-626, 1998.

[49] D. Rinne, R. P. Baum, G. Hör, and R. Kaufmann, "Primary staging and follow-up of high risk melanoma patients with wholebody $18 \mathrm{~F}$-fluorodeoxyglucose positron emission tomography: results of a prospective study of 100 patients," Cancer, vol. 82, no. 9, pp. 1664-1671, 1998.

[50] M. González Cao, J. M. Auge, R. Molina et al., "Melanoma inhibiting activity protein (MIA), beta- 2 microglobulin and lactate dehydrogenase (LDH) in metastatic melanoma," Anticancer Research, vol. 27, no. 1B, pp. 595-599, 2007.

[51] L. L. Yu, T. J. Flotte, K. K. Tanabe et al., "Detection of microscopic melanoma metastases in sentinel lymph nodes," Cancer, vol. 86, no. 4, pp. 617-627, 1999.

[52] M. B. Sporn, N. M. Dunlop, D. L. Newton, and J. M. Smith, "Prevention of chemical carcinogenesis by vitamin A and its synthetic analogs (retinoids)," Federation Proceedings, vol. 35, no. 6, pp. 1332-1338, 1976.
[53] F. L. Meyskens Jr., P. J. Farmer, and H. Anton-Culver, "Etiologic pathogenesis of melanoma: a unifying hypothesis for the missing attributable risk," Clinical Cancer Research, vol. 10, no. 8, pp. 2581-2583, 2004.

[54] A. V. Anstey, "Systemic photoprotection with $\alpha$-tocopherol (vitamin E) and $\beta$-carotene," Clinical and Experimental Dermatology, vol. 27, no. 3, pp. 170-176, 2002.

[55] W. Stahl and H. Sies, "Carotenoids and protection against solar UV radiation," Skin Pharmacology and Applied Skin Physiology, vol. 15, no. 5, pp. 291-296, 2002.

[56] H. Tsao, M. Feldman, J. E. Fullerton, A. J. Sober, D. Rosenthal, and W. Goggins, "Early detection of asymptomatic pulmonary melanoma metastases by routine chest radiographs is not associated with improved survival," Archives of Dermatology, vol. 140, no. 1, pp. 67-70, 2004.

[57] E. Erdei and S. M. Torres, "A new understanding in the epidemiology of melanoma," Expert Review of Anticancer Therapy, vol. 10, no. 11, pp. 1811-1823, 2010.

[58] D. Kavanagh, A. D. K. Hill, B. Djikstra, R. Kennelly, E. M. W. McDermott, and N. J. O'Higgins, "Adjuvant therapies in the treatment of stage II and III malignant melanoma," Surgeon, vol. 3, no. 4, pp. 245-256, 2005.

[59] S. Schreiber, E. Kämpgen, E. Wagner et al., "Immunotherapy of metastatic malignant melanoma by a vaccine consisting of autologous interleukin 2-transfected cancer cells: outcome of a phase I study," Human Gene Therapy, vol. 10, no. 6, pp. 983-993, 1999.

[60] R. W. Dubois, S. M. Swetter, M. Atkins et al., "Developing indications for the use of sentinel lymph node biopsy and adjuvant high-dose interferon alfa-2b in melanoma," Archives of Dermatology, vol. 137, no. 9, pp. 1217-1224, 2001.

[61] H. Tsao, M. B. Atkins, and A. J. Sober, "Management of cutaneous melanoma," The New England Journal of Medicine, vol. 351, no. 10, pp. 998-1012, 2004.

[62] S. Hu, Y. Parmet, G. Allen et al., "Disparity in melanoma: a trend analysis of melanoma incidence and stage at diagnosis among whites, Hispanics, and blacks in Florida," Archives of Dermatology, vol. 145, no. 12, pp. 1369-1374, 2009.

[63] V. K. Sondak and G. T. Gibney, "Indications and options for systemic therapy in melanoma," Surgical Clinics of North America, vol. 94, no. 5, pp. 1049-1058, 2014.

[64] S. Stadler, K. Weina, C. Gebhardt, and J. Utikal, "New therapeutic options for advanced non-resectable malignant melanoma," Advances in Medical Sciences, vol. 60, no. 1, pp. 83-88, 2015.

[65] A. Ribas, A. Hauschild, R. Kefford et al., "Phase III, openlabel, randomized, comparative study of tremelimumab (CP675,206 ) and chemotherapy (temozolomide [TMZ] or dacarbazine [DTIC]) in patients with advanced melanoma," Journal of Clinical Oncology, vol. 26, no. 15, supplement, 2008.

[66] M. A. Postow, J. Chesney, A. C. Pavlick et al., "Nivolumab and ipilimumab versus ipilimumab in untreated melanoma," The New England Journal of Medicine, 2015.

[67] S. Bagcchi, "Pembrolizumab for treatment of refractory melanoma," The Lancet Oncology, vol. 15, no. 10, article e419, 2014.

[68] T. K. Burki, "Variation in prostate cancer management," The Lancet Oncology, vol. 15, no. 10, p. e419, 2014.

[69] B. V. Bonifácio, P. B. da Silva, M. Aparecido dos Santos Ramos, K. Maria Silveira Negri, T. Maria Bauab, and M. Chorilli, "Nanotechnology-based drug delivery systems and herbal medicines: a review," International Journal of Nanomedicine, vol. 9, no. 1, pp. 1-15, 2014. 
[70] R. M. Mainardes, M. C. Cocenza Urban, P. O. Cinto, M. V. Chaud, R. C. Evangelista, and M. P. Daflon Gremião, "Liposomes and micro/nanoparticles as colloidal carriers for nasal drug delivery," Current Drug Delivery, vol. 3, no. 3, pp. 275-285, 2006.

[71] R. N. Saha, S. Vasanthakumar, G. Bende, and M. Snehalatha, "Nanoparticulate drug delivery systems for cancer chemotherapy," Molecular Membrane Biology, vol. 27, no. 7, pp. 215-231, 2010.

[72] A. E. Grill, N. W. Johnston, T. Sadhukha, and J. Panyam, "A review of select recent patents on novel nanocarriers," Recent Patents on Drug Delivery and Formulation, vol. 3, no. 2, pp. 137142, 2009.

[73] J. Venugopal, M. P. Prabhakaran, S. Low et al., "Continuous nanostructures for the controlled release of drugs," Current Pharmaceutical Design, vol. 15, no. 15, pp. 1799-1808, 2009.

[74] V. P. Torchilin, "Multifunctional, stimuli-sensitive nanoparticulate systems for drug delivery," Nature Reviews Drug Discovery, vol. 13, no. 11, pp. 813-827, 2014.

[75] A. Kumar, A. Srivastava, I. Y. Galaev, and B. Mattiasson, "Smart polymers: physical forms and bioengineering applications," Progress in Polymer Science, vol. 32, no. 10, pp. 1205-1237, 2007.

[76] M. P. Patel, S. T. Churchman, A. T. Cruchley, M. Braden, and D. M. Williams, "Delivery of macromolecules across oral mucosa from polymeric hydrogels is enhanced by electrophoresis (iontophoresis)," Dental Materials, vol. 29, no. 11, pp. e299-e307, 2013.

[77] S. Thomas, R. Shanks, and C. Sarathchandran, Nanostructured Polymer Blends, edited by: W. Andrew, Elsevier, Oxford, UK, 1st edition, 2013.

[78] T. R. Hoare and D. S. Kohane, "Hydrogels in drug delivery: progress and challenges," Polymer, vol. 49, no. 8, pp. 1993-2007, 2008.

[79] M. Casolaro, D. B. Barbara, and M. Emilia, "Hydrogel containing l-valine residues as a platform for cisplatin chemotherapy," Colloids and Surfaces B: Biointerfaces, vol. 88, no. 1, pp. 389-395, 2011.

[80] J. L. Drury and D. J. Mooney, "Hydrogels for tissue engineering: scaffold design variables and applications," Biomaterials, vol. 24, no. 24, pp. 4337-4351, 2003.

[81] S. W. Kim, Y. H. Bae, and T. Okano, "Hydrogels: swelling, drug loading, and release," Pharmaceutical Research, vol. 9, no. 3, pp. 283-290, 1992.

[82] R. Vasita and D. S. Katti, "Nanofibers and their applications in tissue engineering," International Journal of Nanomedicine, vol. 1, no. 1, pp. 15-30, 2006.

[83] N. A. Peppas, P. Bures, W. Leobandung, and H. Ichikawa, "Hydrogels in pharmaceutical formulations," European Journal of Pharmaceutics and Biopharmaceutics, vol. 50, no. 1, pp. 27-46, 2000.

[84] D. J. Murphy, M. G. Sankalia, R. G. Loughlin, R. F. Donnelly, M. G. Jenkins, and P. A. Mccarron, "Physical characterisation and component release of poly(vinyl alcohol)-tetrahydroxyborate hydrogels and their applicability as potential topical drug delivery systems," International Journal of Pharmaceutics, vol. 423, no. 2, pp. 326-334, 2012.

[85] N. Bhattarai, J. Gunn, and M. Zhang, "Chitosan-based hydrogels for controlled, localized drug delivery," Advanced Drug Delivery Reviews, vol. 62, no. 1, pp. 83-99, 2010.

[86] Y. Gao, J. Xie, H. Chen et al., "Nanotechnology-based intelligent drug design for cancer metastasis treatment," Biotechnology Advances, vol. 32, no. 4, pp. 761-777, 2014.
[87] M. J. Alvarez-Figueroa and J. Blanco-Méndez, “Transdermal delivery of methotrexate: iontophoretic delivery from hydrogels and passive delivery from microemulsions," International Journal of Pharmaceutics, vol. 215, no. 1-2, pp. 57-65, 2001.

[88] G. Lu and H. W. Jun, "Diffusion studies of methotrexate in Carbopol and Poloxamer gels," International Journal of Pharmaceutics, vol. 160, no. 1, pp. 1-9, 1998.

[89] F. C. Carvalho, G. Calixto, I. N. Hatakeyama, G. M. Luz, M. P. D. Gremião, and M. Chorilli, "Rheological, mechanical, and bioadhesive behavior of hydrogels to optimize skin delivery systems," Drug Development and Industrial Pharmacy, vol. 39, no. 11, pp. 1750-1757, 2013.

[90] G. Calixto, A. C. Yoshii, H. Rocha e Silva, B. S. F. Cury, and M. Chorilli, "Polyacrylic acid polymers hydrogels intended to topical drug delivery: preparation and characterization," Pharmaceutical Development and Technology, 2014.

[91] M. Redpath, C. M. G. Marques, C. Dibden, A. Waddon, R. Lalla, and S. MacNeil, "Ibuprofen and hydrogel-released ibuprofen in the reduction of inflammation-induced migration in melanoma cells," British Journal of Dermatology, vol. 161, no. 1, pp. 25-33, 2009.

[92] M. J. Moura, M. H. Gil, and M. M. Figueiredo, "Delivery of cisplatin from thermosensitive co-cross-linked chitosan hydrogels," European Polymer Journal, vol. 49, no. 9, pp. 2504-2510, 2013.

[93] M. R. Bernsen, J.-W. Tang, L. A. Everse, J. W. Koten, and W. Den Otter, "Interleukin 2 (IL-2) therapy: potential advantages of locoregional versus systemic administration," Cancer Treatment Reviews, vol. 25, no. 2, pp. 73-82, 1999.

[94] G. W. Bos, J. J. L. Jacobs, J. W. Koten et al., "In situ crosslinked biodegradable hydrogels loaded with IL-2 are effective tools for local IL-2 therapy," European Journal of Pharmaceutical Sciences, vol. 21, no. 4, pp. 561-567, 2004.

[95] T. Takei, K. Sugihara, M. Yoshida, and K. Kawakami, "Injectable and biodegradable sugar beet pectin/gelatin hydrogels for biomedical applications," Journal of Biomaterials Science, Polymer Edition, vol. 24, no. 11, pp. 1333-1342, 2013.

[96] E. Ruel-Gariépy, M. Shive, A. Bichara et al., "A thermosensitive chitosan-based hydrogel for the local delivery of paclitaxel," European Journal of Pharmaceutics and Biopharmaceutics, vol. 57, no. 1, pp. 53-63, 2004.

[97] W. S. Shim, J.-H. Kim, K. Kim et al., "pH- and temperaturesensitive, injectable, biodegradable block copolymer hydrogels as carriers for paclitaxel," International Journal of Pharmaceutics, vol. 331, no. 1, pp. 11-18, 2007.

[98] C. C. Beh, R. Mammucari, and N. R. Foster, "Lipids-based drug carrier systems by dense gas technology: a review," Chemical Engineering Journal, vol. 188, pp. 1-14, 2012.

[99] E. Fahy, S. Subramaniam, H. A. Brown et al., "A comprehensive classification system for lipids," Journal of Lipid Research, vol. 46, no. 5, pp. 839-861, 2005.

[100] D.-G. Yu, C. Branford-White, G. R. Williams et al., "Self-assembled liposomes from amphiphilic electrospun nanofibers," Soft Matter, vol. 7, no. 18, pp. 8239-8247, 2011.

[101] S. Zhang, H.-J. Sun, A. D. Hughes et al., "'single-single' amphiphilic janus dendrimers self-assemble into uniform dendrimersomes with predictable size," ACS Nano, vol. 8, no. 2, pp. 1554-1565, 2014.

[102] J. Muñoz and M. C. Alfaro, "Rheological and phase behaviour of amphiphilic lipids," Grasas y Aceites, vol. 51, no. 1-2, pp. 6-25, 2000. 
[103] M. Y. Vagin, E. V. Malyh, N. I. Larionova, and A. A. Karyakin, "Spontaneous and facilitated micelles formation at liquid/liquid interface: towards amperometric detection of redox inactive proteins," Electrochemistry Communications, vol. 5, no. 4, pp. 329-333, 2003.

[104] M. C. Woodle and D. Papahadjopoulos, "Liposome preparation and size characterization," Methods in Enzymology, vol. 171, pp. 193-217, 1989.

[105] W. R. Hargreaves, "Liposomes from ionic, single-chain amphiphiles," Biochemistry, vol. 17, no. 18, pp. 3759-3767, 1978.

[106] F. Frézard, D. A. Schettini, O. G. Rocha, and C. Demicheli, "Lipossomas: propriedades físico-químicas e farmacológicas, aplicações na quimioterapia à base de antimônio," Química Nova, vol. 28, no. 3, pp. 511-518, 2005.

[107] V. P. Torchilin, "Recent advances with liposomes as pharmaceutical carriers," Nature Reviews Drug Discovery, vol. 4, no. 2, pp. 145-160, 2005.

[108] L. C. G. Machado, S. Anne, and M. L. W. Klüppel, "Liposomes applied in pharmacology: a review," Estudos de Biologia, vol. 29, no. 67, pp. 215-224, 2007.

[109] A. N. Jătariu, M. Popa, and C. A. Peptu, "Different particulate systems-bypass the biological barriers," Journal of Drug Targeting, vol. 18, no. 4, pp. 243-253, 2010.

[110] N. Berger, A. Sachse, J. Bender, R. Schubert, and M. Brandl, "Filter extrusion of liposomes using different devices: comparison of liposome size, encapsulation efficiency, and process characteristics," International Journal of Pharmaceutics, vol. 223, no. 1-2, pp. 55-68, 2001.

[111] M. M. Lapinski, A. Castro-Forero, A. J. Greiner, R. Y. Ofoli, and G. J. Blanchard, "Comparison of liposomes formed by sonication and extrusion: rotational and translational diffusion of an embedded chromophore," Langmuir, vol. 23, no. 23, pp. 11677-11683, 2007.

[112] F. Olson, C. A. Hunt, F. C. Szoka, W. J. Vail, and D. Papahadjopoulos, "Preparation of liposomes of defined size distribution by extrusion through polycarbonate membranes," $B B A-$ Biomembranes, vol. 557, no. 1, pp. 9-23, 1979.

[113] E. Feitosa, P. C. A. Barreleiro, and G. Olofsson, "Phase transition in dioctadecyldimethylammonium bromide and chloride vesicles prepared by different methods," Chemistry and Physics of Lipids, vol. 105, no. 2, pp. 201-213, 2000.

[114] D. G. Hunter and B. J. Frisken, "Effect of extrusion pressure and lipid properties on the size and polydispersity of lipid vesicles," Biophysical Journal, vol. 74, no. 6, pp. 2996-3002, 1998.

[115] G. Maulucci, M. De Spirito, G. Arcovito, F. Boffi, A. C. Castellano, and G. Briganti, "Particle distribution in DMPC vesicles solutions undergoing different sonication times," Biophysical Journal, vol. 88, no. 5, pp. 3545-3550, 2005.

[116] M. Owais and C. M. Gupta, "Targeted drug delivery to macrophages in parasitic infections," Current Drug Delivery, vol. 2, no. 4, pp. 311-318, 2005.

[117] R. A. Schwendener, "Liposomes in biology and medicine," Advances in Experimental Medicine and Biology, vol. 620, pp. 117-128, 2007.

[118] S. Bhowmick, R. Ravindran, and N. Ali, "Leishmanial antigens in liposomes promote protective immunity and provide immunotherapy against visceral leishmaniasis via polarized Th1 response," Vaccine, vol. 25, no. 35, pp. 6544-6556, 2007.

[119] S. E. Treiger Borborema, R. A. Schwendener, J. A. Osso Junior, H. F. de Andrade Junior, and N. do Nascimento, "Uptake and antileishmanial activity of meglumine antimoniatecontaining liposomes in Leishmania (Leishmania) majorinfected macrophages," International Journal of Antimicrobial Agents, vol. 38, no. 4, pp. 341-347, 2011.

[120] P. Wolf, H. Maier, R. R. Müllegger et al., “Topical treatment with liposomes containing $\mathrm{T} 4$ endonuclease $\mathrm{V}$ protects human skin in vivo from ultraviolet-induced upregulation of interleukin-10 and tumor necrosis factor- $\alpha$," Journal of Investigative Dermatology, vol. 114, no. 1, pp. 149-156, 2000.

[121] D. Yarosh, J. Klein, A. O'Connor, J. Hawk, E. Rafal, and P. Wolf, "Effect of topically applied T4 endonuclease V in liposomes on skin cancer in xeroderma pigmentosum: a randomised study," The Lancet, vol. 357, no. 9260, pp. 926-929, 2001.

[122] M. B. Pierre, A. C. Tedesco, J. M. Marchetti, and M. V. Bentley, "Stratum corneum lipids liposomes for the topical delivery of 5-aminolevulinic acid in photodynamic therapy of skin cancer: preparation and in vitro permeation study," BMC Dermatology, vol. 1, no. 1, p. 5, 2001.

[123] Y. Chen, Q. Wu, Z. Zhang, L. Yuan, X. Liu, and L. Zhou, "Preparation of curcumin-loaded liposomes and evaluation of their skin permeation and pharmacodynamics," Molecules, vol. 17, no. 5, pp. 5972-5987, 2012.

[124] M. Nobayashi, M. Mizuno, T. Kageshita, K. Matsumoto, T. Saida, and J. Yoshida, "Repeated cationic multilamellar liposome-mediated gene transfer enhanced transduction efficiency against murine melanoma cell lines," Journal of Dermatological Science, vol. 29, no. 3, pp. 206-213, 2002.

[125] D. Liu, H. Hu, Z. Lin et al., "Quercetin deformable liposome: preparation and efficacy against ultraviolet B induced skin damages in vitro and in vivo," Journal of Photochemistry and Photobiology B: Biology, vol. 127, pp. 8-17, 2013.

[126] E. M. M. Del Valle, "Cyclodextrins and their uses: a review," Process Biochemistry, vol. 39, no. 9, pp. 1033-1046, 2004.

[127] M. Singh, R. Sharma, and U. C. Banerjee, "Biotechnological applications of cyclodextrins," Biotechnology Advances, vol. 20, no. 5-6, pp. 341-359, 2002.

[128] A. L. Laza-Knoerr, R. Gref, and P. Couvreur, "Cyclodextrins for drug delivery," Journal of Drug Targeting, vol. 18, no. 9, pp. 645656, 2010.

[129] A. Biwer, G. Antranikian, and E. Heinzle, "Enzymatic production of cyclodextrins," Applied Microbiology and Biotechnology, vol. 59, no. 6, pp. 609-617, 2002.

[130] T. Loftsson and D. Duchêne, "Cyclodextrins and their pharmaceutical applications," International Journal of Pharmaceutics, vol. 329, no. 1-2, pp. 1-11, 2007.

[131] T. Loftsson and M. E. Brewster, "Pharmaceutical applications of cyclodextrins. 1. Drug solubilization and stabilization," Journal of Pharmaceutical Sciences, vol. 85, no. 10, pp. 1017-1025, 1996.

[132] T. Loftsson, M. Másson, and M. E. Brewster, "Self-association of cyclodextrins and cyclodextrin complexes," Journal of Pharmaceutical Sciences, vol. 93, no. 5, pp. 1091-1099, 2004.

[133] J. Zhang and P. X. Ma, "Host-guest interactions mediated nanoassemblies using cyclodextrin-containing hydrophilic polymers and their biomedical applications," Nano Today, vol. 5, no. 4, pp. 337-350, 2010.

[134] K. Uekama, "Design and evaluation of cyclodextrin-based drug formulation," Chemical and Pharmaceutical Bulletin, vol. 52, no. 8, pp. 900-915, 2004.

[135] B. Gidwani and A. Vyas, "Synthesis, characterization and application of epichlorohydrin- $\beta$-cyclodextrin polymer," Colloids and Surfaces B: Biointerfaces, vol. 114, pp. 130-137, 2014. 
[136] N. C. Bellocq, S. H. Pun, G. S. Jensen, and M. E. Davis, "Transferrin-containing, cyclodextrin polymer-based particles for tumor-targeted gene delivery," Bioconjugate Chemistry, vol. 14, no. 6, pp. 1122-1132, 2003.

[137] S. Hu-Lieskovan, J. D. Heidel, D. W. Bartlett, M. E. Davis, and T. J. Triche, "Sequence-specific knockdown of EWS-FLI1 by targeted, nonviral delivery of small interfering RNA inhibits tumor growth in a murine model of metastatic Ewing's sarcoma," Cancer Research, vol. 65, no. 19, pp. 8984-8992, 2005.

[138] S. H. Pun, F. Tack, N. C. Bellocq et al., "Targeted delivery of RNA-cleaving DNA enzyme (DNAzyme) to tumor tissue by transferrin-modified, cyclodextrin-based particles," Cancer Biology and Therapy, vol. 3, no. 7, pp. 641-650, 2004.

[139] D. Michel, J. M. Chitanda, R. Balogh et al., "Design and evaluation of cyclodextrin-based delivery systems to incorporate poorly soluble curcumin analogs for the treatment of melanoma," European Journal of Pharmaceutics and Biopharmaceutics, vol. 81, no. 3, pp. 548-556, 2012.

[140] S. Ganta, H. Devalapally, A. Shahiwala, and M. Amiji, "A review of stimuli-responsive nanocarriers for drug and gene delivery," Journal of Controlled Release, vol. 126, no. 3, pp. 187-204, 2008.

[141] I. F. Tannock and D. Rotin, "Acid pH in tumors and its potential for therapeutic exploitation," Cancer Research, vol. 49, no. 16, pp. 4373-4384, 1989.

[142] Y. Liu, W. Wang, J. Yang, C. Zhou, and J. Sun, "pH-sensitive polymeric micelles triggered drug release for extracellular and intracellular drug targeting delivery," Asian Journal of Pharmaceutical Sciences, vol. 8, no. 3, pp. 159-167, 2013.

[143] Z. Zhang, J. Ding, X. Chen et al., "Intracellular pH-sensitive supramolecular amphiphiles based on host-guest recognition between benzimidazole and $\beta$-cyclodextrin as potential drug delivery vehicles," Polymer Chemistry, vol. 4, no. 11, pp. 32653271, 2013.

[144] H. He, S. Chen, J. Zhou et al., "Cyclodextrin-derived pHresponsive nanoparticles for delivery of paclitaxel," Biomaterials, vol. 34, no. 21, pp. 5344-5358, 2013.

[145] F. Huang and H. W. Gibson, "Polypseudorotaxanes and polyrotaxanes," Progress in Polymer Science, vol. 30, no. 10, pp. 9821018, 2005.

[146] J. Chang, Y. Li, G. Wang, B. He, and Z. Gu, "Fabrication of novel coumarin derivative functionalized polypseudorotaxane micelles for drug delivery," Nanoscale, vol. 5, no. 2, pp. 813-820, 2013.

[147] Z.-H. Chen and E. Niki, "4-Hydroxynonenal (4-HNE) has been widely accepted as an inducer of oxidative stress. Is this the whole truth about it or can 4 -HNE also exert protective effects?" IUBMB Life, vol. 58, no. 5-6, pp. 372-373, 2006.

[148] W. Siems and T. Grune, "Intracellular metabolism of 4hydroxynonenal," Molecular Aspects of Medicine, vol. 24, no. 45, pp. 167-175, 2003.

[149] S. Pizzimenti, E. Ciamporcero, P. Pettazzoni et al., "The inclusion complex of 4-hydroxynonenal with a polymeric derivative of $\beta$-cyclodextrin enhances the antitumoral efficacy of the aldehyde in several tumor cell lines and in a three-dimensional human melanoma model," Free Radical Biology and Medicine, vol. 65, pp. 765-777, 2013.

[150] S. K. Rodal, G. Skretting, Ø. Garred, F. Vilhardt, B. van Deurs, and K. Sandvig, "Extraction of cholesterol with methyl- $\beta$ cyclodextrin perturbs formation of clathrin-coated endocytic vesicles," Molecular Biology of the Cell, vol. 10, no. 4, pp. 961974, 1999.
[151] I. S. Babina, S. Donatello, I. R. Nabi, and A. M. Hopkins, "Lipid rafts as master regulators of breast cancer cell function," in Breast Cancer-Carcinogenesis, Cell Growth and Signalling Pathways, M. Gunduz and E. Gunduz, Eds., chapter 19, InTech, 2011.

[152] T. Murai, Y. Maruyama, K. Mio, H. Nishiyama, M. Suga, and C. Sato, "Low cholesterol triggers membrane microdomaindependent CD44 shedding and suppresses tumor cell migration," Journal of Biological Chemistry, vol. 286, no. 3, pp. 19992007, 2011.

[153] P. Keller and K. Simons, "Cholesterol is required for surface transport of influenza virus hemagglutinin," Journal of Cell Biology, vol. 140, no. 6, pp. 1357-1367, 1998.

[154] R. Onodera, K. Motoyama, A. Okamatsu et al., "Involvement of cholesterol depletion from lipid rafts in apoptosis induced by methyl- $\beta$-cyclodextrin," International Journal of Pharmaceutics, vol. 452, no. 1-2, pp. 116-123, 2013.

[155] A. Mazzaglia, M. L. Bondì, A. Scala et al., "Supramolecular assemblies based on complexes of nonionic amphiphilic cyclodextrins and a meso-tetra(4-sulfonatophenyl)porphine tributyltin(IV) derivative: potential nanotherapeutics against melanoma," Biomacromolecules, vol. 14, no. 11, pp. 3820-3829, 2013.

[156] G. S. Kienle and H. Kiene, "Complementary cancer therapy: a systematic review of prospective clinical trials on anthroposophic mistletoe extracts," European Journal of Medical Research, vol. 12, no. 3, pp. 103-119, 2007.

[157] E. Ernst, "The role of complementary and alternative medicine in cancer," The Lancet Oncology, vol. 1, no. 3, pp. 176-180, 2000.

[158] C. M. Strüh, S. Jäger, A. Kersten, C. M. Schempp, A. Scheffler, and S. F. Martin, "Triterpenoids amplify anti-tumoral effects of mistletoe extracts on murine B16.f10 melanoma in vivo," PLoS ONE, vol. 8, no. 4, Article ID e62168, 2013.

[159] R. H. Cichewicz and S. A. Kouzi, "Chemistry, biological activity, and chemotherapeutic potential of betulinic acid for the prevention and treatment of cancer and HIV infection," Medicinal Research Reviews, vol. 24, no. 1, pp. 90-114, 2004.

[160] C. Şoica, C. Dehelean, C. Danciu et al., "Betulin complex in $\gamma$ cyclodextrin derivatives: properties and antineoplasic activities in in vitro and in vivo tumor models," International Journal of Molecular Sciences, vol. 13, no. 11, pp. 14992-15011, 2012.

[161] C. Nicholas and G. B. Lesinski, "Immunomodulatory cytokines as therapeutic agents for melanoma," Immunotherapy, vol. 3, no. 5, pp. 673-690, 2011.

[162] R. A. Flavell, S. Sanjabi, S. H. Wrzesinski, and P. Licona-Limón, "The polarization of immune cells in the tumour environment by TGF $\beta$," Nature Reviews Immunology, vol. 10, no. 8, pp. 554567, 2010.

[163] J. Park, S. H. Wrzesinski, E. Stern et al., "Combination delivery of TGF- $\beta$ inhibitor and IL- 2 by nanoscale liposomal polymeric gels enhances tumour immunotherapy," Nature Materials, vol. 11, no. 10, pp. 895-905, 2012.

[164] S. B. Brown, E. A. Brown, and I. Walker, “The present and future role of photodynamic therapy in cancer treatment," The Lancet Oncology, vol. 5, no. 8, pp. 497-508, 2004.

[165] H. Kolarova, J. Macecek, P. Nevrelova et al., "Photodynamic therapy with zinc-tetra(p-sulfophenyl)porphyrin bound to cyclodextrin induces single strand breaks of cellular DNA in G361 melanoma cells," Toxicology in Vitro, vol. 19, no. 7, pp. 971974, 2005. 
[166] S. S. Guterres, M. P. Alves, and A. R. Pohlmann, "Polymeric nanoparticles, nanospheres and nanocapsules, for cutaneous applications," Drug Target Insights, vol. 2, pp. 147-157, 2007.

[167] V. Mohanraj and Y. Chen, "Nanoparticles-a review," Tropical Journal of Pharmaceutical Research, vol. 5, no. 1, pp. 561-573, 2006.

[168] H. Bhargava, A. Narurkar, and L. Lieb, "Using microemulsions for drug delivery," Pharmaceutical Technology, vol. 11, no. 3, pp. 46-54, 1987.

[169] T. P. Formariz, M. C. Urban, A. A. Silva Júnior, M. P. Gremião, and A. G. Oliveira, "Microemulsões e fases líquidas cristalinas como sistemas de liberação de fármacos," Revista Brasileira de Ciências Farmacêuticas, vol. 41, no. 3, pp. 301-313, 2005.

[170] M. Chorilli, P. S. Prestes, R. B. Rigon, G. R. Leonardi, L. A. Chiavacci, and M. V. Scarpa, "Desenvolvimento de sistemas líquido-cristalinos empregando silicone fluido de co-polímero glicol e poliéter funcional siloxano," Química Nova, vol. 32, no. 4, pp. 1036-1040, 2009.

[171] C. C. Mueller-Goymann and S. G. Frank, "Interaction of lidocaine and lidocaine- $\mathrm{HCl}$ with the liquid crystal structure of topical preparations," International Journal of Pharmaceutics, vol. 29, no. 2-3, pp. 147-159, 1986.

[172] O. Lehmann, Flüssige Kristalle, Wilhelm Engelmann, Leipzig, Germany, 1904.

[173] M. Ferrari, "Obtenção e aplicação de emulsões múltiplas contendo óleo de andiroba e copaíba," in Faculdade de Ciências Farmacêuticas de Ribeirão Preto, p. 147, Sao Paulo University, Ribeirão Preto, Brazil, 1998.

[174] M. Urban, "Desenvolvimento de sistemas de liberação micro e nanoestruturados para administração cutânea do acetato de dexametasona," in Drugs and Medicines, p. 136, São Paulo State University, Araraquara, Brazil, 2004.

[175] L. Bitan-Cherbakovsky, A. Aserin, and N. Garti, "Structural characterization of lyotropic liquid crystals containing a dendrimer for solubilization and release of gallic acid," Colloids and Surfaces B, vol. 112, pp. 87-95, 2013.

[176] M. Gosenca, M. Bešter-Rogač, and M. Gašperlin, "Lecithin based lamellar liquid crystals as a physiologically acceptable dermal delivery system for ascorbyl palmitate," European Journal of Pharmaceutical Sciences, vol. 50, no. 1, pp. 114-122, 2013.

[177] D. Bei, J. Marszalek, and B.-B. C. Youan, "Formulation of dacarbazine-loaded cubosomes-part I: influence of formulation variables," AAPS PharmSciTech, vol. 10, no. 3, pp. 10321039, 2009.

[178] D. Bei, T. Zhang, J. B. Murowchick, and B.-B. C. Youan, "Formulation of dacarbazine-loaded cubosomes. Part III. physicochemical characterization," AAPS PharmSciTech, vol. 11, no. 3, pp. 1243-1249, 2010.

[179] X. Gong, M. J. Moghaddam, S. M. Sagnella et al., "Lyotropic liquid crystalline self-assembly material behavior and nanoparticulate dispersions of a phytanyl pro-drug analogue of capecitabine-a chemotherapy agent," ACS Applied Materials \& Interfaces, vol. 3, no. 5, pp. 1552-1561, 2011.

[180] K. L. von Eckardstein, S. Patt, C. Kratzel, J. C. W. Kiwit, and R. Reszka, "Local chemotherapy of F98 rat glioblastoma with paclitaxel and carboplatin embedded in liquid crystalline cubic phases," Journal of Neuro-Oncology, vol. 72, no. 3, pp. 209-215, 2005.

[181] K. L. von Eckardstein, R. Reszka, and J. C. Kiwit, "Intracavitary chemotherapy (paclitaxel/carboplatin liquid crystalline cubic phases) for recurrent glioblastoma-clinical observations," Journal of Neuro-Oncology, vol. 74, no. 3, pp. 305-309, 2005.

[182] S. B. Rizwan, Y.-D. Dong, B. J. Boyd, T. Rades, and S. Hook, "Characterisation of bicontinuous cubic liquid crystalline systems of phytantriol and water using cryo field emission scanning electron microscopy (cryo FESEM)," Micron, vol. 38, no. 5, pp. 478-485, 2007.

[183] N. Zeng, Q. Hu, Z. Liu et al., "Preparation and characterization of paclitaxel-loaded DSPE-PEG-liquid crystalline nanoparticles (LCNPs) for improved bioavailability," International Journal of Pharmaceutics, vol. 424, no. 1-2, pp. 58-66, 2012.

[184] D. Bei, J. Marszalek, and B.-B. C. Youan, "Formulation of dacarbazine-loaded cubosomes-part II: influence of process parameters," AAPS PharmSciTech, vol. 10, no. 3, pp. 1040-1047, 2009.

[185] L. Mu and S. S. Feng, "A novel controlled release formulation for the anticancer drug paclitaxel (Taxol): PLGA nanoparticles containing vitamin E TPGS," Journal of Controlled Release, vol. 86, no. 1, pp. 33-48, 2003.

[186] A. Pampel, D. Michel, and R. Reszka, "Pulsed field gradient MAS-NMR studies of the mobility of carboplatin in cubic liquid-crystalline phases," Chemical Physics Letters, vol. 357, no. 1-2, pp. 131-136, 2002.

[187] A. Dowling, R. Clift, N. Grobert et al., "Nanoscience and nanotechnologies: opportunities and uncertainties," The Royal Society \& The Royal Academy of Engineering Report, Royal Academy of Engineering, London, UK, 2004.

[188] P. K. Jain, K. S. Lee, I. H. El-Sayed, and M. A. El-Sayed, "Calculated absorption and scattering properties of gold nanoparticles of different size, shape, and composition: applications in biological imaging and biomedicine," The Journal of Physical Chemistry B, vol. 110, no. 14, pp. 7238-7248, 2006.

[189] K. A. Howard, U. L. Rahbek, X. Liu et al., "RNA interference in vitro and in vivo using a novel chitosan/siRNA nanoparticle system," Molecular Therapy, vol. 14, no. 4, pp. 476-484, 2006.

[190] P. L. Apopa, Y. Qian, R. Shao et al., "Iron oxide nanoparticles induce human microvascular endothelial cell permeability through reactive oxygen species production and microtubule remodeling," Particle and Fibre Toxicology, vol. 6, no. 1, article 1, 2009.

[191] M. Auffan, J. Rose, J.-Y. Bottero, G. V. Lowry, J.-P. Jolivet, and M. R. Wiesner, "Towards a definition of inorganic nanoparticles from an environmental, health and safety perspective," Nature Nanotechnology, vol. 4, no. 10, pp. 634-641, 2009.

[192] Food and Drug Administration (FDA), Guidance for Industry: Assessing the Effects of Significant Manufacturing Process Changes, Including Emerging Technologies, on the Safety and Regulatory Status of Food Ingredients and Food Contact Substances, Including Food Ingredients That are Color Additives, Food and Drug Administration (FDA), Silver Spring, Md, USA, 2012.

[193] R. Müller and J. Lucks, "Arzneistoffträger aus festen lipidteilchen, feste lipidnanosphären $(\operatorname{sln})$," European Patent, 1996.

[194] R. H. Müller, R. D. Petersen, A. Hommoss, and J. Pardeike, "Nanostructured lipid carriers (NLC) in cosmetic dermal products," Advanced Drug Delivery Reviews, vol. 59, no. 6, pp. 522530, 2007.

[195] W. Mehnert and K. Mäder, "Solid lipid nanoparticles: production, characterization and applications," Advanced Drug Delivery Reviews, vol. 47, no. 2-3, pp. 165-196, 2001. 
[196] E. B. Souto, A. J. Almeida, and R. H. Müller, "Lipid nanoparticles (SLN, NLC) for cutaneous drug delivery: structure, protection and skin effects," Journal of Biomedical Nanotechnology, vol. 3, no. 4, pp. 317-331, 2007.

[197] Y.-C. Kuo and C.-C. Wang, "Cationic solid lipid nanoparticles with primary and quaternary amines for release of saquinavir and biocompatibility with endothelia," Colloids and Surfaces B: Biointerfaces, vol. 101, pp. 101-105, 2013.

[198] Y.-C. Kuo and C.-T. Liang, "Catanionic solid lipid nanoparticles carrying doxorubicin for inhibiting the growth of U87MG cells," Colloids and Surfaces B: Biointerfaces, vol. 85, no. 2, pp. 131-137, 2011.

[199] F. Canfarotta, M. J. Whitcombe, and S. A. Piletsky, "Polymeric nanoparticles for optical sensing," Biotechnology Advances, vol. 31, no. 8, pp. 1585-1599, 2013.

[200] C.-M. J. Hu and L. Zhang, "Nanoparticle-based combination therapy toward overcoming drug resistance in cancer," Biochemical Pharmacology, vol. 83, no. 8, pp. 1104-1111, 2012.

[201] H. Fessi, F. Piusieux, J. P. Devissaguet, N. Ammoury, and S. Benita, "Nanocapsule formation by interfacial polymer deposition following solvent displacement," International Journal of Pharmaceutics, vol. 55, no. 1, pp. R1-R4, 1989.

[202] N. Al Khouri Fallouh, L. Roblot-Treupel, and H. Fessi, "Development of a new process for the manufacture of polyisobutylcyanoacrylate nanocapsules," International Journal of Pharmaceutics, vol. 28, no. 2-3, pp. 125-132, 1986.

[203] B. Magenheim and S. Benita, "Nanoparticle characterization: a comprehensive physicochemical approach," STP Pharma Sciences, vol. 1, no. 4, pp. 221-241, 1991.

[204] K. S. Soppimath, T. M. Aminabhavi, A. R. Kulkarni, and W. E. Rudzinski, "Biodegradable polymeric nanoparticles as drug delivery devices," Journal of Controlled Release, vol. 70, no. 1-2, pp. 1-20, 2001.

[205] G. Orive, E. Anitua, J. L. Pedraz, and D. F. Emerich, "Biomaterials for promoting brain protection, repair and regeneration," Nature Reviews Neuroscience, vol. 10, no. 9, pp. 682-692, 2009.

[206] K. Letchford and H. Burt, "A review of the formation and classification of amphiphilic block copolymer nanoparticulate structures: micelles, nanospheres, nanocapsules and polymersomes," European Journal of Pharmaceutics and Biopharmaceutics, vol. 65, no. 3, pp. 259-269, 2007.

[207] D. Hanahan and R. A. Weinberg, "Hallmarks of cancer: the next generation," Cell, vol. 144, no. 5, pp. 646-674, 2011.

[208] A. Jain, K. Jain, P. Kesharwani, and N. K. Jain, "Low density lipoproteins mediated nanoplatforms for cancer targeting," Journal of Nanoparticle Research, vol. 15, no. 9, article 1888, 38 pages, 2013.

[209] H. Hillaireau and P. Couvreur, "Nanocarriers' entry into the cell: relevance to drug delivery," Cellular and Molecular Life Sciences, vol. 66, no. 17, pp. 2873-2896, 2009.

[210] J. H. Sakamoto, A. L. van de Ven, B. Godin et al., "Enabling individualized therapy through nanotechnology," Pharmacological Research, vol. 62, no. 2, pp. 57-89, 2010.

[211] Y.-C. Kuo and H.-H. Chen, "Effect of electromagnetic field on endocytosis of cationic solid lipid nanoparticles by human brain-microvascular endothelial cells," Journal of Drug Targeting, vol. 18, no. 6, pp. 447-456, 2010.

[212] D. E. Owens III and N. A. Peppas, "Opsonization, biodistribution, and pharmacokinetics of polymeric nanoparticles," International Journal of Pharmaceutics, vol. 307, no. 1, pp. 93102, 2006.
[213] A. Gabizon and F. Martin, "Polyethylene glycol-coated (pegylated) liposomal doxorubicin. Rationale for use in solid tumours," Drugs, vol. 54, no. 4, pp. 15-21, 1997.

[214] T. Ameller, V. Marsaud, P. Legrand, R. Gref, G. Barratt, and J.-M. Renoir, "Polyester-poly(ethylene glycol) nanoparticles loaded with the pure antiestrogen RU 58668: physicochemical and opsonization properties," Pharmaceutical Research, vol. 20, no. 7, pp. 1063-1070, 2003.

[215] K. Na, E. S. Lee, and Y. H. Bae, "Adriamycin loaded pullulan acetate/sulfonamide conjugate nanoparticles responding to tumor $\mathrm{pH}$ : $\mathrm{pH}$-dependent cell interaction, internalization and cytotoxicity in vitro," Journal of Controlled Release, vol. 87, no. 1-3, pp. 3-13, 2003.

[216] F. Sonvico, S. Mornet, S. Vasseur et al., "Folate-conjugated iron oxide nanoparticles for solid tumor targeting as potential specific magnetic hyperthermia mediators: synthesis, physicochemical characterization, and in vitro experiments," Bioconjugate Chemistry, vol. 16, no. 5, pp. 1181-1188, 2005.

[217] H. L. Wong, R. Bendayan, A. M. Rauth, H. Y. Xue, K. Babakhanian, and X. Y. Wu, "A mechanistic study of enhanced doxorubicin uptake and retention in multidrug resistant breast cancer cells using a polymer-lipid hybrid nanoparticle system," Journal of Pharmacology and Experimental Therapeutics, vol. 317, no. 3, pp. 1372-1381, 2006.

[218] E. Ristorcelli, E. Beraud, P. Verrando et al., "Human tumor nanoparticles induce apoptosis of pancreatic cancer cells," The FASEB Journal, vol. 22, no. 9, pp. 3358-3369, 2008.

[219] R. A. Parlo and P. S. Coleman, "Enhanced rate of citrate export from cholesterol-rich hepatoma mitochondria. The truncated Krebs cycle and other metabolic ramifications of mitochondrial membrane cholesterol," Journal of Biological Chemistry, vol. 259, no. 16, pp. 9997-10003, 1984.

[220] H. L. Wong, R. Bendayan, A. M. Rauth, Y. Li, and X. Y. Wu, "Chemotherapy with anticancer drugs encapsulated in solid lipid nanoparticles," Advanced Drug Delivery Reviews, vol. 59, no. 6, pp. 491-504, 2007.

[221] Y. Noguchi, J. Wu, R. Duncan et al., "Early phase tumor accumulation of Macromolecules: a great difference in clearance rate between tumor and normal tissues," Japanese Journal of Cancer Research, vol. 89, no. 3, pp. 307-314, 1998.

[222] A. K. Iyer, G. Khaled, J. Fang, and H. Maeda, "Exploiting the enhanced permeability and retention effect for tumor targeting," Drug Discovery Today, vol. 11, no. 17-18, pp. 812-818, 2006.

[223] H. Maeda, J. Wu, T. Sawa, Y. Matsumura, and K. Hori, “Tumor vascular permeability and the EPR effect in macromolecular therapeutics: a review," Journal of Controlled Release, vol. 65, no. 1-2, pp. 271-284, 2000.

[224] Z. Xu, L. Chen, W. Gu et al., "The performance of docetaxelloaded solid lipid nanoparticles targeted to hepatocellular carcinoma," Biomaterials, vol. 30, no. 2, pp. 226-232, 2009.

[225] J. Dausend, A. Musyanovych, M. Dass et al., "Uptake mechanism of oppositely charged fluorescent nanoparticles in HeLa cells," Macromolecular Bioscience, vol. 8, no. 12, pp. 1135-1143, 2008.

[226] E. Chang, N. Thekkek, W. W. Yu, V. L. Colvin, and R. Drezek, "Evaluation of quantum dot cytotoxicity based on intracellular uptake," Small, vol. 2, no. 12, pp. 1412-1417, 2006.

[227] T. Xia, M. Kovochich, M. Liong, J. I. Zink, and A. E. Nel, "Cationic polystyrene nanosphere toxicity depends on cellspecific endocytic and mitochondrial injury pathways," ACS Nano, vol. 2, no. 1, pp. 85-96, 2008. 
[228] L. Guo, Y. Peng, J. Yao, L. Sui, A. Gu, and J. Wang, "Anticancer activity and molecular mechanism of resveratrol-bovine serum albumin nanoparticles on subcutaneously implanted human primary ovarian carcinoma cells in nude mice," Cancer Biotherapy and Radiopharmaceuticals, vol. 25, no. 4, pp. 471-477, 2010.

[229] K. Teskač and J. Kristl, "The evidence for solid lipid nanoparticles mediated cell uptake of resveratrol," International Journal of Pharmaceutics, vol. 390, no. 1, pp. 61-69, 2010.

[230] Z.-R. Huang, S.-C. Hua, Y.-L. Yang, and J.-Y. Fang, "Development and evaluation of lipid nanoparticles for camptothecin delivery: a comparison of solid lipid nanoparticles, nanostructured lipid carriers, and lipid emulsion," Acta Pharmacologica Sinica, vol. 29, no. 9, pp. 1094-1102, 2008.

[231] D. Liu, Z. Liu, L. Wang, C. Zhang, and N. Zhang, "Nanostructured lipid carriers as novel carrier for parenteral delivery of docetaxel," Colloids and Surfaces B: Biointerfaces, vol. 85, no. 2, pp. 262-269, 2011.

[232] S.-H. Hsu, C.-J. Wen, S. A. Al-Suwayeh, Y.-J. Huang, and J.Y. Fang, "Formulation design and evaluation of quantum dotloaded nanostructured lipid carriers for integrating bioimaging and anticancer therapy," Nanomedicine, vol. 8, no. 8, pp. 12531269, 2013.

[233] K. S. Ho and M. S. Shoichet, "Design considerations of polymeric nanoparticle micelles for chemotherapeutic delivery," Current Opinion in Chemical Engineering, vol. 2, no. 1, pp. 53-59, 2013.

[234] H. Yao, S. S. Ng, L.-F. Huo et al., "Effective melanoma immunotherapy with interleukin-2 delivered by a novel polymeric nanoparticle," Molecular Cancer Therapeutics, vol. 10, no. 6, pp. 1082-1092, 2011.

[235] A. R. Khuda-Bukhsh, S. S. Bhattacharyya, S. Paul, and N. Boujedaini, "Polymeric nanoparticle encapsulation of a naturally occurring plant scopoletin and its effects on human melanoma cell A375," Journal of Chinese Integrative Medicine, vol. 8, no. 9, pp. 853-862, 2010.

[236] S. Das, J. Das, A. Samadder, A. Paul, and A. R. Khuda-Bukhsh, "Strategic formulation of apigenin-loaded PLGA nanoparticles for intracellular trafficking, DNA targeting and improved therapeutic effects in skin melanoma in vitro," Toxicology Letters, vol. 223, no. 2, pp. 124-138, 2013.

[237] D. Vieira, V. Kim, D. Petri, C. Menck, and A. Carmona-Ribeiro, "Polymer-based delivery vehicle for cisplatin," Nanotechnology, vol. 3, pp. 382-385, 2011.

[238] V. Mailänder, M. R. Lorenz, V. Holzapfel et al., "Carboxylated superparamagnetic iron oxide particles label cells intracellularly without transfection agents," Molecular Imaging and Biology, vol. 10, no. 3, pp. 138-146, 2008.

[239] A. Ades, J. P. Carvalho, S. R. Graziani et al., "Uptake of a cholesterol-rich emulsion by neoplastic ovarian tissues," Gynecologic Oncology, vol. 82, no. 1, pp. 84-87, 2001.

[240] D. Gal, M. Ohashi, P. C. MacDonald, H. J. Buchsbaum, and E. R. Simpson, "Low-density lipoprotein as a potential vehicle for chemotherapeutic agents and radionucleotides in the management of gynecologic neoplasms," American Journal of Obstetrics and Gynecology, vol. 139, no. 8, pp. 877-885, 1981.

[241] M. J. Rudling, V. P. Collins, and C. O. Peterson, "Delivery of aclacinomycin A to human glioma cells in vitro by the lowdensity lipoprotein pathway," Cancer Research, vol. 43, no. 10, pp. 4600-4605, 1983.
[242] M. Masquelier, S. Vitols, and C. Peterson, "Low-density lipoprotein as a carrier of antitumoral drugs: in vivo fate of drughuman-low-density lipoprotein complexes in mice," Cancer Research, vol. 46, no. 8, pp. 3842-3847, 1986.

[243] B. Lundberg, "Preparation of drug low density lipoprotein complexes for delivery of antitumoral drugs via the low density lipoprotein pathway," Cancer Research, vol. 47, no. 15, pp. 41054108, 1987.

[244] H. Jin, J. F. Lovell, J. Chen et al., "Cytosolic delivery of LDL nanoparticle cargo using photochemical internalization," Photochemical and Photobiological Sciences, vol. 10, no. 5, pp. 810-816, 2011.

[245] R. R. Allison and K. Moghissi, "Oncologic photodynamic therapy: clinical strategies that modulate mechanisms of action," Photodiagnosis and Photodynamic Therapy, vol. 10, no. 4, pp. 331-341, 2013.

[246] C. J. Field and P. D. Schley, "Evidence for potential mechanisms for the effect of conjugated linoleic acid on tumor metabolism and immune function: lessons from n-3 fatty acids," The American Journal of Clinical Nutrition, vol. 79, no. 6, pp. 1190S1198S, 2004.

[247] J. S. Falconer, J. A. Ross, K. C. H. Fearon, R. A. Hawkins, M. G. O'Riordain, and D. C. Carter, "Effect of eicosapentaenoic acid and other fatty acids on the growth in vitro of human pancreatic cancer cell lines," British Journal of Cancer, vol. 69, no. 5, pp. 826-832, 1994.

[248] S. Jaracz, J. Chen, L. V. Kuznetsova, and I. Ojima, "Recent advances in tumor-targeting anticancer drug conjugates," Bioorganic and Medicinal Chemistry, vol. 13, no. 17, pp. 5043-5054, 2005.

[249] X.-Y. Yang, Y.-X. Li, M. Li, L. Zhang, L.-X. Feng, and N. Zhang, "Hyaluronic acid-coated nanostructured lipid carriers for targeting paclitaxel to cancer," Cancer Letters, vol. 334, no. 2, pp. 338-345, 2013.

[250] K. Y. Choi, H. Chung, K. H. Min et al., "Self-assembled hyaluronic acid nanoparticles for active tumor targeting," Biomaterials, vol. 31, no. 1, pp. 106-114, 2010.

[251] K. Y. Choi, K. H. Min, H. Y. Yoon et al., "PEGylation of hyaluronic acid nanoparticles improves tumor targetability in vivo," Biomaterials, vol. 32, no. 7, pp. 1880-1889, 2011.

[252] J. D. Byrne, T. Betancourt, and L. Brannon-Peppas, "Active targeting schemes for nanoparticle systems in cancer therapeutics," Advanced Drug Delivery Reviews, vol. 60, no. 15, pp. 1615-1626, 2008.

[253] J. F. Kukowska-Latallo, K. A. Candido, Z. Cao et al., "Nanoparticle targeting of anticancer drug improves therapeutic response in animal model of human epithelial cancer," Cancer Research, vol. 65, no. 12, pp. 5317-5324, 2005.

[254] C. P. Leamon and J. A. Reddy, "Folate-targeted chemotherapy," Advanced Drug Delivery Reviews, vol. 56, no. 8, pp. 1127-1141, 2004.

[255] Y. Malam, M. Loizidou, and A. M. Seifalian, "Liposomes and nanoparticles: nanosized vehicles for drug delivery in cancer," Trends in Pharmacological Sciences, vol. 30, no. 11, pp. 592-599, 2009.

[256] D. Labarre, C. Vauthier, C. Chauvierre, B. Petri, R. Müller, and M. M. Chehimi, "Interactions of blood proteins with poly(isobutylcyanoacrylate) nanoparticles decorated with a polysaccharidic brush," Biomaterials, vol. 26, no. 24, pp. 50755084, 2005.

[257] R.-L. Hong, C.-J. Huang, Y.-L. Tseng et al., "Direct comparison of liposomal doxorubicin with or without polyethylene glycol 
coating in C-26 tumor-bearing mice: is surface coating with polyethylene glycol beneficial?” Clinical Cancer Research, vol. 5, no. 11, pp. 3645-3652, 1999.

[258] Y. Sheng, C. Liu, Y. Yuan et al., "Long-circulating polymeric nanoparticles bearing a combinatorial coating of PEG and water-soluble chitosan," Biomaterials, vol. 30, no. 12, pp. 23402348, 2009.

[259] S. Krasnici, A. Werner, M. E. Eichhorn et al., "Effect of the surface charge of liposomes on their uptake by angiogenic tumor vessels," International Journal of Cancer, vol. 105, no. 4, pp. 561-567, 2003.

[260] R. Kunstfeld, G. Wickenhauser, U. Michaelis et al., "Paclitaxel encapsulated in cationic liposomes diminishes tumor angiogenesis and melanoma growth in a 'humanized' SCID mouse model," Journal of Investigative Dermatology, vol. 120, no. 3, pp. 476-482, 2003.

[261] S. Ran, A. Downes, and P. E. Thorpe, "Increased exposure of anionic phospholipids on the surface of tumor blood vessels," Cancer Research, vol. 62, no. 21, pp. 6132-6140, 2002.

[262] A. S. Hoffman, "Hydrogels for biomedical applications," Advanced Drug Delivery Reviews, vol. 64, pp. 18-23, 2012.

[263] T. P. Chelvi and R. Ralhan, "Designing of thermosensitive liposomes from natural lipids for multimodality cancer therapy," International Journal of Hyperthermia, vol. 11, no. 5, pp. 685695, 1995

[264] S. Batzri and E. D. Korn, "Single bilayer liposomes prepared without sonication," Biochimica et Biophysica ActaBiomembranes, vol. 298, no. 4, pp. 1015-1019, 1973.

[265] J. J. Escobar-Chávez, "Nanocarriers for transdermal drug delivery," Skin, vol. 19, p. 22, 2012.

[266] M. R. Mozafari, "Liposomes: an overview of manufacturing techniques," Cellular and Molecular Biology Letters, vol. 10, no. 4, pp. 711-719, 2005.

[267] M. Malmsten, "Soft drug delivery systems," Soft Matter, vol. 2, no. 9, pp. 760-769, 2006.

[268] R. A. Rajewski and V. J. Stella, "Pharmaceutical applications of cyclodextrins. 2. In vivo drug delivery," Journal of Pharmaceutical Sciences, vol. 85, no. 11, pp. 1142-1169, 1996.

[269] A. F. Soares, R. D. A. Carvalho, and F. Veiga, "Oral administration of peptides and proteins: nanoparticles and cyclodextrins as biocompatible delivery systems," Nanomedicine, vol. 2, no. 2 , pp. 183-202, 2007.

[270] P. S. Prestes, M. Chorilli, L. A. Chiavacci, M. V. Scarpa, and G. R. Leonardi, "Physicochemical characterization and rheological behavior evaluation of the liquid crystalline mesophases developed with different silicones," Journal of Dispersion Science and Technology, vol. 31, no. 1, pp. 117-123, 2009.

[271] M. Rückert and G. Otting, "Alignment of biological macromolecules in novel nonionic liquid crystalline media for NMR experiments," Journal of the American Chemical Society, vol. 122, no. 32, pp. 7793-7797, 2000.

[272] E. B. Souto, P. Severino, M. H. A. Santana, and S. C. Pinho, "Solid lipid nanoparticles: classical methods of lab production," Quimica Nova, vol. 34, no. 10, pp. 1762-1769, 2011.

[273] S. Shi, L. Han, L. Deng et al., "Dual drugs (microRNA34a and paclitaxel)-loaded functional solid lipid nanoparticles for synergistic cancer cell suppression," Journal of Controlled Release, vol. 194, pp. 228-237, 2014.

[274] L. Mazzarino, L. F. C. Silva, J. C. Curta et al., "Curcuminloaded lipid and polymeric nanocapsules stabilized by nonionic surfactants: an in vitro and in vivo antitumor activity on B16-F10 melanoma and macrophage uptake comparative study," Journal of Biomedical Nanotechnology, vol. 7, no. 3, pp. 406-414, 2011.

[275] L. Cai, X. Wang, W. Wang et al., "Peptide ligand and PEGmediated long-circulating liposome targeted to FGFR overexpressing tumor in vivo," International Journal of Nanomedicine, vol. 7, pp. 4499-4510, 2012.

[276] Y. Barenholz, "Doxil-The first FDA-approved nano-drug: lessons learned," Journal of Controlled Release, vol. 160, no. 2, pp. 117-134, 2012.

[277] A. S. Yang and P. B. Chapman, "The history and future of chemotherapy for melanoma," Hematology/Oncology Clinics of North America, vol. 23, no. 3, pp. 583-597, 2009.

[278] M. Ugurel, D. Schadendorf, W. Fink et al., "Clinical phase II study of pegylated liposomal doxorubicin as second-line treatment in disseminated melanoma," Onkologie, vol. 27, no. 6, pp. 540-544, 2004.

[279] W.-J. Hwu, K. S. Panageas, J. H. Menell et al., "Phase II study of temozolomide plus pegylated interferon- $\alpha-2 b$ for metastatic melanoma," Cancer, vol. 106, no. 11, pp. 2445-2451, 2006.

[280] P. Decuzzi and M. Ferrari, "The receptor-mediated endocytosis of nonspherical particles," Biophysical Journal, vol. 94, no. 10, pp. 3790-3797, 2008.

[281] H. K. Sajja, M. P. East, H. Mao, Y. A. Wang, S. Nie, and L. Yang, "Development of multifunctional nanoparticles for targeted drug delivery and noninvasive imaging of therapeutic effect," Current Drug Discovery Technologies, vol. 6, no. 1, pp. 43-51, 2009.

[282] D. Rosenblum and D. Peer, "Omics-based nanomedicine: the future of personalized oncology," Cancer Letters, vol. 352, no. 1, pp. 126-136, 2013. 

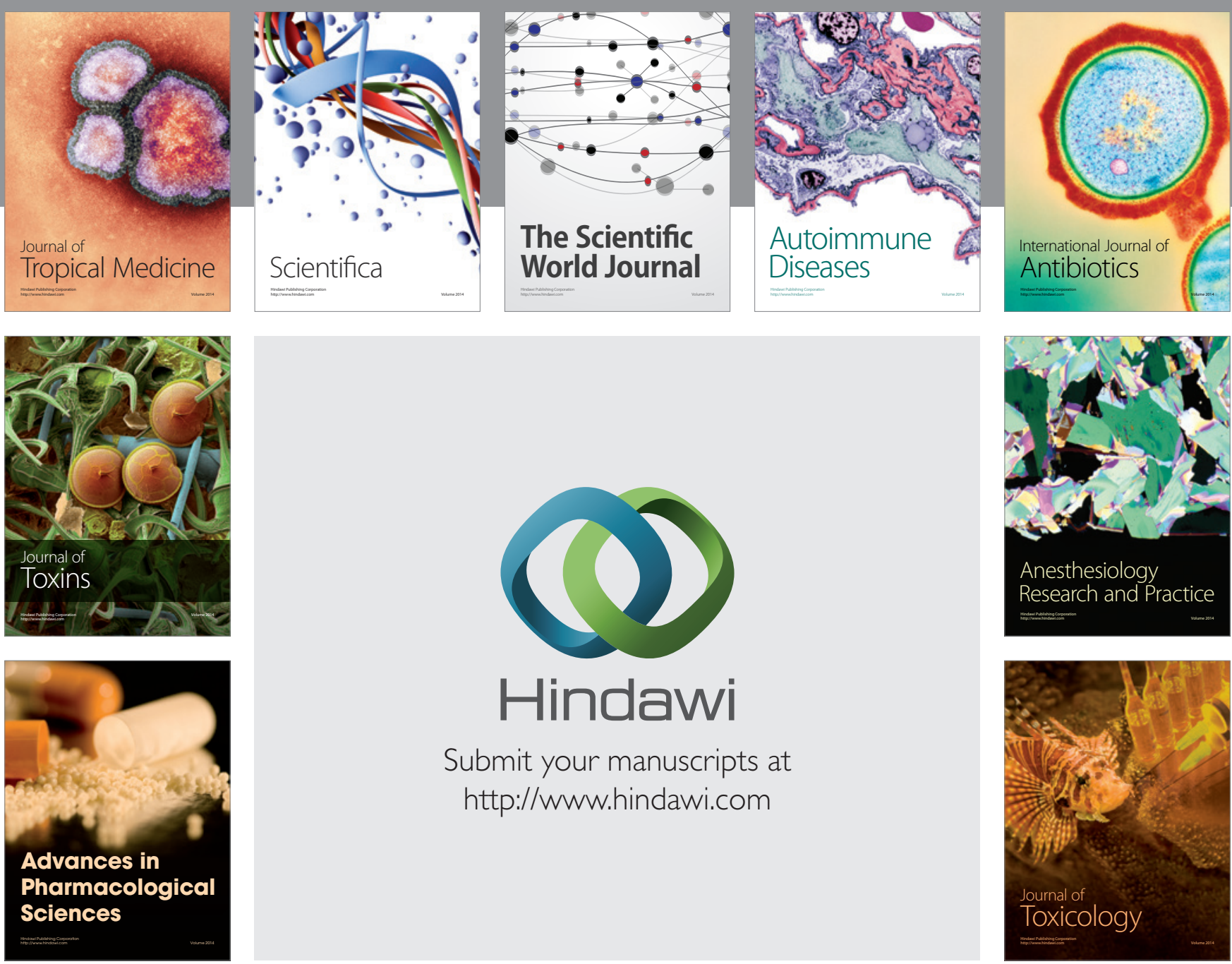

\section{Hindawi}

Submit your manuscripts at

http://www.hindawi.com
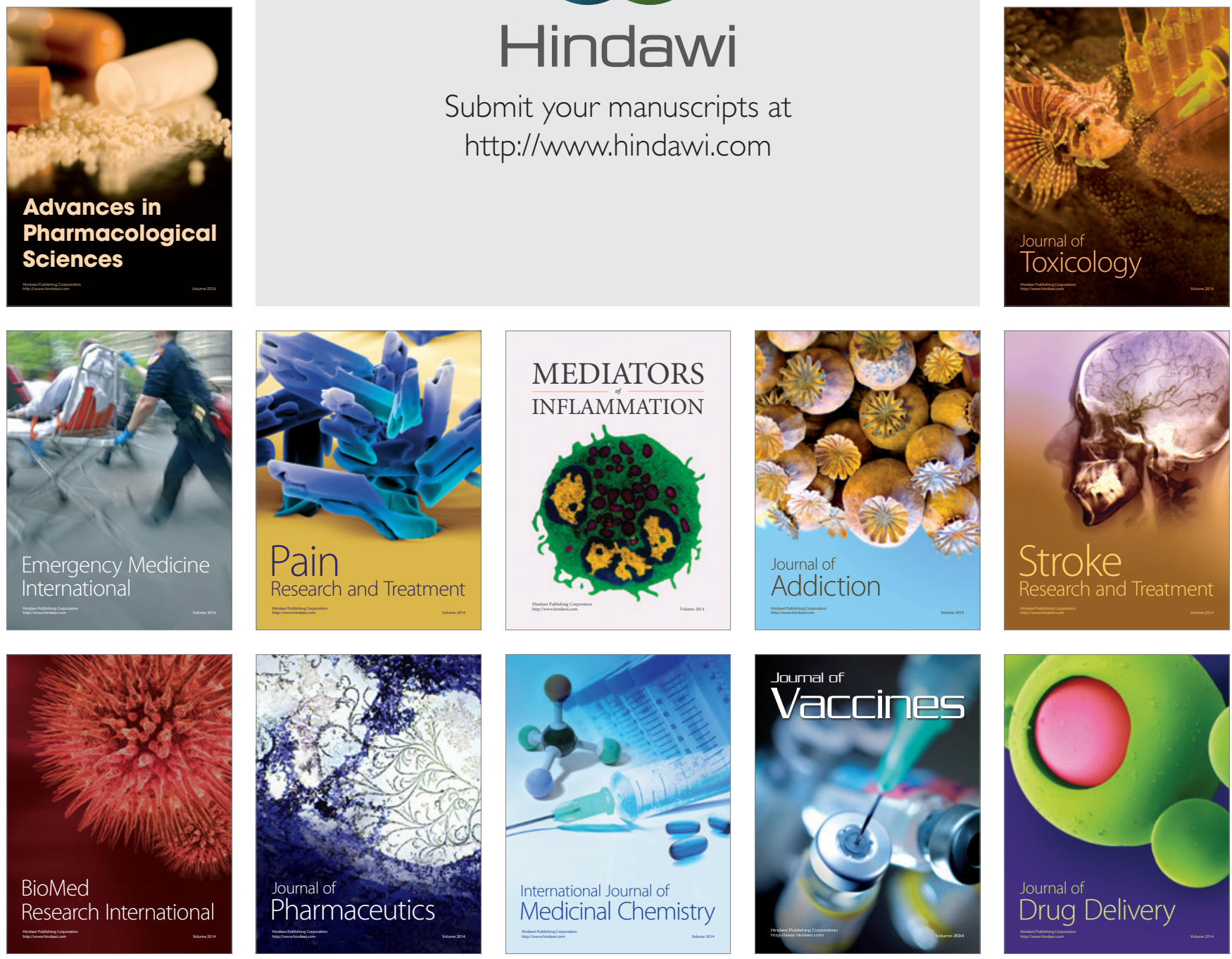